\title{
From State-to-Trait Meditation: Reconfiguration of Central Executive and Default Mode Networks
}

\author{
(1)C. C. C. Bauer, ${ }^{1,2,3,4}$ S. Whitfield-Gabrieli, ${ }^{1,4}$ J. L. Díaz, ${ }^{5}$ E. H. Pasaye, ${ }^{2}$ and ${ }^{-P F}$ A. Barrios ${ }^{1,2}$
}

https://doi.org/10.1523/ENEURO.0335-18.2019

${ }^{1}$ McGovern Institute for Brain Research, MIT, Cambridge 02139, MA, ${ }^{2}$ Instituto de Neurobiología, Universidad
Nacional Autónoma de México, Querétaro, QRO 76230, México, ${ }^{3}$ Cognitive Neuroscience Laboratory at Boston VA
Healthcare System, Brockton 02130, MA, ${ }^{4}$ Department of Psychology, Northeastern University, Boston 02115 , MA,
and ${ }^{5}$ Facultad de Medicina, Universidad Nacional Autónoma de México, Ciudad de México 04510, México

\begin{abstract}
While brain default mode network (DMN) activation in human subjects has been associated with mind wandering, meditation practice has been found to suppress it and to increase psychological well-being. In addition to DMN activity reduction, experienced meditators (EMs) during meditation practice show an increased connectivity between the DMN and the central executive network (CEN). However, the gradual change between DMN and CEN configuration from pre-meditation, during meditation, and post-meditation is unknown. Here, we investigated the change in DMN and CEN configuration by means of brain activity and functional connectivity (FC) analyses in EMs across three back-to-back functional magnetic resonance imaging (fMRl) scans: pre-meditation baseline (trait), meditation (state), and post-meditation (state-to-trait). Pre-meditation baseline group comparison was also performed between EMs and healthy controls (HCs). Meditation trait was characterized by a significant reduction in activity and FC within DMN and increased anticorrelations between DMN and CEN. Conversely, meditation state and meditation state-to-trait periods showed increased activity and FC within the DMN and between DMN and CEN. However, the latter anticorrelations were only present in EMs with limited practice. The interactions between networks during these states by means of positive diametric activity (PDA) of the fractional amplitude of low-frequency fluctuations (fALFFs) defined as $\overline{C E N ~ f A L F F}-\overline{D M N} f A L F F$ revealed no trait differences but significant increases during meditation state that persisted in meditation state-to-trait. The gradual reconfiguration in DMN and CEN suggest a neural mechanism by which the CEN negatively regulates the DMN and is probably responsible for the long-term trait changes seen in meditators and reported psychological well-being.
\end{abstract}

Key words: experienced meditators; fALFF; functional connectivity; mind-wandering; mindfulness; top-down control

\section{Significance Statement}

We introduce a positive diametric activity (PDA) metric to measure the relation between two anticorrelated rs-fMRI networks in experienced meditators (EMs). PDA as well as functional connectivity $(\mathrm{FC})$ are increased during meditation compared to resting state and persists in the post-meditation resting state. Conversely, meditation trait is characterized by positive PDA but with significant reduction in activity and FC within default mode network (DMN) and increased anticorrelations between DMN and central executive network (CEN). PDA and FC between DMN and CEN distinguish meditation state-to-trait effects.

Received August 28, 2018; accepted October 8, 2019; First published November 6, 2019.

The authors declare no competing financial interests.
Author contributions: C.C.C.B., J.L.D., and F.A.B. designed research; C.C.C.B., E.H.P., and F.A.B. performed research; C.C.C.B., S.W.-G., E.H.P., and F.A.B. analyzed data; C.C.C.B., S.W.-G., J.L.D., E.H.P., and F.A.B. wrote 


\section{Introduction}

What does the mind do when all physiologic needs are taken care of and there are no immediate demands? Does it part into an empty void, a dormant state to conserve resources until something disturbs it and activity is needed? We all know that this is not the case. Every moment of our waking experience challenges this explanation of mental life. When nothing requires active cogitative processing, our mind generally tends to think about what is not going on in the present moment, i.e., it wanders, recapitulates events that happened in the past, or fantasizes about what might happen in the future, jumping from one thought to the next with amazing speed and apparent randomness (Mason et al., 2007). Undeniably, this never stopping stream of consciousness appears to be our brain's idle mode of being, our default mode when not otherwise engaged (Mason et al., 2007; Christoff et al., 2016; Kane et al., 2017). Although this ability is as an evolutionary achievement that allows us to learn, reason, and plan (Mantini et al., 2013; Rilling, 2014), it swiftly fails to serve its adaptive function, and turns into a risk factor for health and psychological well-being whenever it becomes a rigid and inflexible pattern with tremendous emotional costs (Smallwood et al., 2009; Killingsworth and Gilbert, 2010; Ottaviani et al., 2013; Simon and Engström, 2015; Jazaieri et al., 2016). Consequently, the underlying mental processes that keep the brain active when not otherwise engaged have been a source of significant theoretical surmise. Since the advent of neurophysiological recordings, it has been determined that the brain is never truly at rest (Berger and Hans, 1933). From a functional imaging perspective, the remarkable properties of the brain's intrinsic activity were first noted by Biswal et al. (1995). They observed that the "noise" in the spontaneous functional magnetic resonance imaging (fMRI) blood oxygen level-dependent (BOLD) signal exhibited striking patterns of spatial coherence corresponding, in their case, to the sensorimotor regions of the cerebral cortex. Subsequently, Raichle and colleagues first took notice that during the commonly used "baseline" in research paradigms, the synchronous behavior of a number of anatomic regions were observed to deactivate during task and thus initially identified as a network of task-specific deactivations, later named the default mode network (DMN; Gusnard et al., 2001; Buckner et al., 2008). Soon it was determined that these task specific deactiva-

the paper; S.W.-G. and F.A.B. contributed unpublished reagents/analytic tools.

This work was supported by the National Council of Science and Technology, Mexico (Consejo Nacional de Ciencia y Tecnología, CONACYT) Grant CB167271 and by the CONACYT 250718 Doctoral Fellowship.

Acknowledgements: We thank MSc Leopoldo González-Santos, MSc Juan J. Ortiz, and Dr. Sarael Alcauter for technical support and Dr. M.C. Jeziorski for his manuscript editing.

Correspondence should be addressed to F. A. Barrios at fbarrios@unam.mx or C. C. C. Bauer at cccbauer@mit.edu.

https://doi.org/10.1523/ENEURO.0335-18.2019

Copyright (C) 2019 Bauer et al.

This is an open-access article distributed under the terms of the Creative Commons Attribution 4.0 International license, which permits unrestricted use, distribution and reproduction in any medium provided that the original work is properly attributed. tions of the DMN also showed patterns of coherent activation during periods of rest that included anterior (medial prefrontal cortex, MPFC) and posterior midline structures (posterior cingulate, PCC) as well as lateral temporal cortex (LTC) and the hippocampus. Additionally, in healthy individuals, DMN activity has been shown to be anticorrelated (negatively correlated) with brain regions activated during attention demanding tasks (e.g., the central executive network, CEN; Greicius et al., 2003; Fox et al., 2005; Fransson, 2005; Kelly et al., 2008; Uddin et al., 2009). Specifically, the CEN, typically including the dorsolateral prefrontal cortex (DLPFC) and posterior parietal cortex (PPC), supports these attention demanding tasks, i.e., attentional control and working memory. Across individuals greater magnitude of DMN-CEN anticorrelations is associated with superior cognitive function such as complex working memory (Whitfield-Gabrieli et al., 2009; Hampson et al., 2010; Keller et al., 2015). Abnormal DMN activity, such as competitive, antagonistic DMN activation during CEN activity or changes in connectivity between subregions of the DMN, has also been associated not only with lower levels of happiness (Killingsworth and Gilbert, 2010; Smallwood and O'Connor, 2011), but with a number of psychological disorders such as anxiety (Zhao et al., 2007), depression (Sheline et al., 2009), schizophrenia (Garrity, 2007; Pomarol-Clotet et al., 2008; WhitfieldGabrieli et al., 2009; Camchong et al., 2011; Bastos-Leite et al., 2015), epilepsy (Liao et al., 2011), autism (Assaf et al., 2010), attention deficit hyperactivity disorder (ADHD; Uddin et al., 2008), and Alzheimer's disease (AD; Greicius et al., 2004; Sheline and Raichle, 2013). Recent studies further suggest that abnormal DMN activity and connectivity plays a role in neuropsychiatric disorders (Whitfield-Gabrieli and Ford, 2012; Raichle, 2015). These associations have led to the suggestion of using the DMN as method by which to study mental disorders, resulting in a growing body of literature concerning disorderspecific variations within the DMN (Arens et al., 2003; Greicius, 2008; Broyd et al., 2009; Fox and Greicius, 2010; Whitfield-Gabrieli and Ford, 2012; Simon and Engström, 2015).

Given the interrelationship between mind-wandering, DMN activity, and the risk to health and psychological well-being, a question arises: Is it possible to change this maladaptive mode into one that is more pleasant and healthier? According to many philosophical and contemplative traditions, yes, this is possible. Thus, these teach that happiness is to be found by "living in the moment," i.e., to be here and now without losing oneself in past or future thought. For more than two millennia, meditation has been practiced as a means of achieving this ephemeral mind state, psychological equanimity, and selfawareness, yet it has only recently become the target of systematic Western-world research for its relevance to mental and physical health in fields such as medicine, psychology, and neuroscience (Van Dam et al., 2018). Undeniably, meditation is becoming increasingly well regarded for its therapeutic promise (Buchholz, 2015; Creswell, 2015; Gu et al., 2015; Simon and Engström, 2015) and meditation methods have been beneficial in the treat- 
ment of psychological disorders such as schizophrenia (Chien and Thompson, 2014), depression (Teasdale et al., 2000; $\mathrm{Ma}$ and Teasdale, 2004; Eisendrath et al., 2008; Kuyken et al., 2008; Yang et al., 2016), anxiety (Baer, 2003; Grossman et al., 2004; Ludwig and Kabat-Zinn, 2008; Shen et al., 2014), addiction (Bowen et al., 2014), alcoholism (Witkiewitz et al., 2005; Garland et al., 2010), smoking (Tang et al., 2013), mild cognitive impairment (MCl; Wells et al., 2013), and ADHD (Zylowska et al., 2008; Bueno et al., 2015; Janssen et al., 2015). Preliminary findings have suggested that the effects of meditation include better emotion regulation (Lutz et al., 2014; Turner, 2014; Prakash et al., 2015), self-regulation (Tang et al., 2014), awareness and self-perception (Hölzel et al., 2011b), memory and cognition (Zeidan et al., 2010), attention (Moore et al., 2012), working memory (Mrazek et al., 2013; Banks et al., 2015), as well as gray and white matter differences in experienced meditators (EMs; Luders et al., 2009; Hölzel et al., 2011a; Fox et al., 2014). Functional imaging studies on meditation practice have examined two distinct effects of meditation. The first, called a state effect, refers to the short-term consequences of meditation practice on the individual's state. This would include short lived changes in bodily awareness, relaxation, emotion regulation, attention and in BOLD activation or functional connectivity $(F C)$ when measured with $\mathrm{fMRI}$. During this active state of meditation, studies have consistently found that within-network connectivity of the DMN as well as between-network connectivity of DMN, CEN and salience network (SAL) are increased (Brewer et al., 2011; Jang et al., 2011; Garrison et al., 2014; Jao et al., 2016). The second, called a trait effect, refers to long-lasting changes in these same dimensions, which continue after practice and during the meditator's daily life (Lutz et al., 2007). However, the findings for this trait effect have not been so clear when measured with resting-state $\mathrm{FC}$ ( $\mathrm{rsFC}$ ), with mixed results (for review, see Mooneyham et al., 2016). Furthermore, little to nothing is known about the activity and connectivity change of DMN and CEN that intertwine the transitory state effects of meditation with the lasting trait effects of meditation practice.

Here, we hypothesized that activity of the CEN is an important modulator of DMN activity and connectivity, both during the meditation state and during the transition phase post-meditation. Support for this idea comes on the one hand from correlational neuroimaging studies looking into attentional and cognitive control (McKiernan et al., 2003; Fox et al., 2005; Fransson, 2005; Dosenbach et al., 2007; Northoff et al., 2007; Sonuga-Barke and Castellanos, 2007; Sridharan et al., 2008; Anticevic et al., 2012), but specifically from a study by Chen et al. (2013) that provides direct evidence for this neural mechanism. In their study, they specifically tested this mechanism by exciting or inhibiting nodes within the CEN using noninvasive brain stimulation and observed the results using simultaneous brain imaging. They found that the DMN is under inhibitory control specifically from a node in CEN (posterior middle frontal gyrus pMFG; BA 9/10). Accordingly, we predicted that brain activation in nodes of the
CEN during meditation would: (1) modulate activity of the $\mathrm{DMN}$ and increase connectivity between DMN and CEN, (2) these changes would persist after meditation and finally, (3) that there are trait differences in DMN and CEN activity and connectivity characteristic of meditation experience. To test these predictions, we conducted three back-to-back fMRI runs in EMs: pre-meditation baseline (trait), meditation (state), and post-meditation (state-totrait). The pre-meditation baseline was also performed on a group of healthy controls (HCs) as a comparison.

\section{Materials and Methods}

\section{Participants}

After standard exclusion criteria for fMRI research were applied, 16 EMs (six females, mean age 41.12 years, SD 10.5, average of $1677 \pm 367 \mathrm{~h}$ of Vipassana meditation experience) and 17 meditation naive HCs (seven females, mean age 35.70 years, SD 4.7) participated in the study. There was no significant age difference between groups $\left(t_{(21)}=-1.68, p=0.10\right)$. All subject groups were recruited and scanned in the same time period as part of the same experiment and all subjects gave informed consent for the experimental procedure, and the protocol had IRB approval.

\section{Experiment design}

BOLD fMRI data were collected from all participants during a 5-min, eyes-open resting-state period (rsBase). In addition, immediately following the rsBase scan, EM participants were also scanned during a 20-min, eyes-open period while engaged in Vipassana meditation (Med). Vipassana meditation emphasizes focused attention typically involving the deliberate focus of attention to a chosen target, such as general body sensations or sensations related to breathing, and the voluntary redirection of attention each time it lapses (Hart, 2011). Finally, EM underwent a second 5-min eyes-open resting-state period (rsPost).

\section{Meditation trait, state, and state-to-trait operationalizations (Austin, 1999; Shapiro and Walsh, 1984; West, 2016) \\ Meditation trait}

The lasting changes in sensory, cognitive, and selfreferential awareness and their underlying brain activity and connectivity that persist in the meditator irrespective of being actively engaged in meditation. Contrast $\mathrm{HC}$ rsBase $<$ EM rsBase (Fig. 1Ca).

\section{Meditation state}

Refers to the altered sensory, cognitive, and selfreferential awareness that can arise during meditation practice and their underlying brain activity and connectivity. In the present study this will correspond to the contrast EM rsBase < EM Med (Fig. 1Cb).

\section{Meditation state-to-trait}

Refers to the changes in sensory, cognitive, and selfreferential awareness and their underlying brain activity and connectivity that persist in the meditator after an active engaged meditation session. Contrast EM rsBase $<$ EM rsPost (Fig. 1CC). 


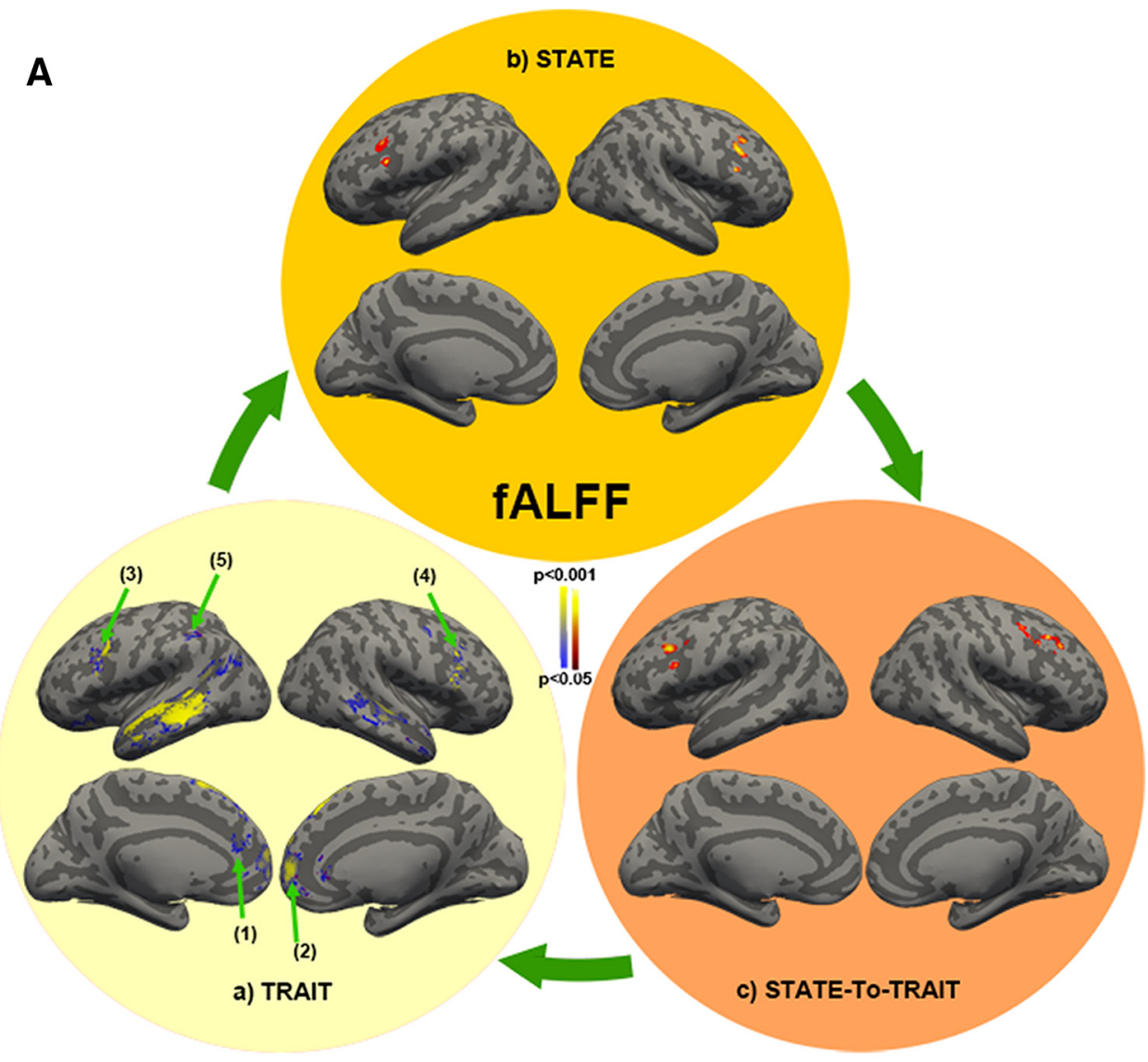

B

C

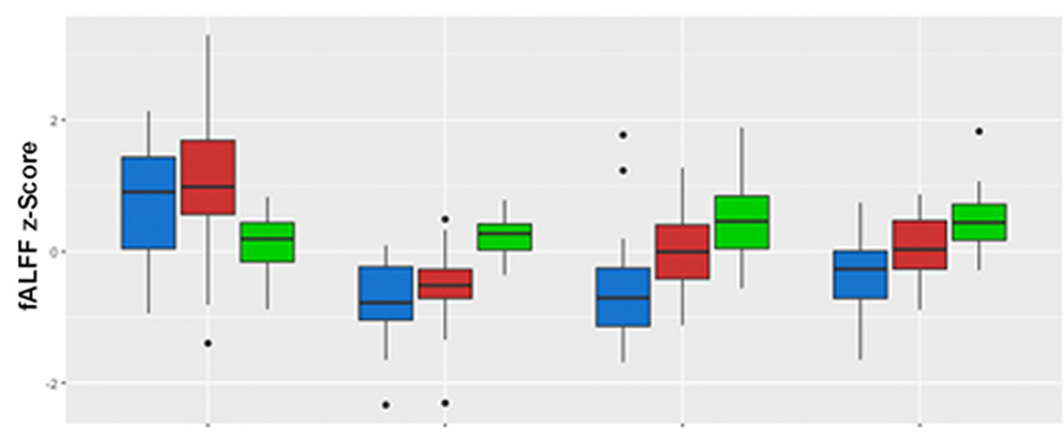

$\mathrm{HC}$ rsBase

EM rsBase

EM Med

EM rsPost

\section{Contrasts}

\section{a) TRAIT}

b) STATE

c) STATE TO TRAIT

HC rsBase < EM rsBase

$\begin{array}{ccc}\text { EM rsBase } & <\text { EM Med } & \\ \text { EM rsBase } & < & \text { EM rsPost }\end{array}$

Figure 1. State-to-trait meditation brain activity changes of the fractional Amplitude of Low-Frequency Fluctuations (fALFFs). Aa, Brain regions showing trait changes in fALFF between meditators and $\mathrm{HCs}$ at baseline (HC rsBase $<\mathrm{EM}$ rsBase). Ab, Brain regions that show significant changes in fALFF during the meditation state in meditators (EM rsBase $<$ EM Med). Ac, Brain regions that show significant changes in fALFF during the transition from state-to-trait meditation in meditators (EM rsBase $<$ EM rsPost). B, Boxplot showing the mean fALFF z-scores in blue (DMN) and red (CEN) and PDA scores in green during baseline (rsBase), meditation (Med) and post-meditation (rsPost) for HCs and EMs. C, Schematic representation of state-to-trait contrasts. All stats shown are nonparametric (5000 permutations) with height threshold $p<0.05$ and cluster-size FDR-corrected $p<0.05$. Black dots represent subjects that lie beyond the whiskers. 


\section{MRI data acquisition}

MRI imaging was performed on a 3.0T GE MR750 instrument (General Electric) using a 32-channel head coil. Functional imaging for resting state included 35 slices, acquired using a T2*-weighted EPI sequence with TR/TE 2000/40 ms, a $64 \times 64$ matrix and $4-\mathrm{mm}$ slice thickness, resulting in a $4 \times 4 \times 4 \mathrm{~mm}^{3}$ isometric voxel and a total of 151 volumes. For meditation imaging included 35 slices, acquired using a T2*-weighted EPI sequence with TR/TE $1500 / 40 \mathrm{~ms}$, a $64 \times 64$ matrix and 4 -mm slice thickness, resulting in a $4 \times 4 \times 4 \mathrm{~mm}^{3}$ isometric voxel and a total of 804 volumes. The shorter TR during meditation was chosen according to the parameters in Hasenkamp et al. (2012) to adhere to additional experiential sampling during meditation and thus needed a faster acquisition. Importantly, this discrepancy has been shown not to affect fractional amplitude of lowfrequency fluctuation (fALFF) nor FC correlation coefficients (CCs) since multiple repetition times have been empirically compared to address the issue of temporal mismatch (Wu et al., 2011). Additionally, high-resolution structural 3D-T1-weighted images were acquired for anatomic localization (resolution of $1 \times 1 \times 1 \mathrm{~mm}^{3}, \mathrm{TR}=2.3$ $\mathrm{s}$, TE $=3 \mathrm{~ms}$ ) covering the whole brain. The images were acquired with an acceleration factor $=2$.

\section{Preprocessing}

The preprocessing of resting-state images was done using SPM 12 software (http://www.fil.ion.ucl.ac.uk/spm) implemented in a MATLAB suite (MathWorks, Inc.). It included slice time correction, head motion correction, co-registration to subjects' structural images, segmentation, normalization, linear detrending, and smoothing $(\mathrm{FWHM}=8 \mathrm{~mm})$.

\section{Brain activity analysis}

To detect regional brain activity changes we used an improved approach of the ALFFs method, fALFF (Zou et al., 2008). This method takes the ratio of power spectrum of low-frequency (here: $0.008-0.09 \mathrm{~Hz}$ ) to that of the entire frequency range. fALFF analysis was conducted with AFNI's 3dRSFC (Taylor and Saad, 2013). Similar to the procedures of previous literature (Zou et al., 2008; Shpaner et al., 2014; Kong et al., 2015), the time series of each voxel was transformed to a frequency domain after the linear trend was removed without bandpass filtering. The square root was then calculated at each frequency of the power spectrum, and finally the sum of amplitude across $0.008-0.09 \mathrm{~Hz}$ was divided by that across the entire frequency range $(0-0.25 \mathrm{~Hz}$ for $\mathrm{TR}=2 \mathrm{~s}$ and $0-0.33 \mathrm{~Hz}$ for TR $=1.5 \mathrm{~s}$, see fMRI data acquisition) to obtain fALFF. Importantly, the TR discrepancy has been shown not to affect fALFF since multiple repetition times have been empirically compared to address the issue of temporal mismatch (Wu et al., 2011). Next, we obtained the meditation trait differences of the fALFF maps of HC and EM at baseline (rsBase) using two-sample $t$ tests. The thresholded images were then converted into binarized masks and were used as the target regions of interest (ROIs) from which to extract the mean fALFF maps for all subjects and states. All imaging analysis were performed with FSL's randomize tool for nonparametric permutation (5000 permutations) inference on neuroimaging data (Winkler et al., 2014) and masked with the binarized DMN and CEN templates of Yeo et al. (2011) and threshold-free cluster enhancement (TFCE; Smith and Nichols, 2009) cluster corrected $(p<0.05)$. We first obtained the meditation trait differences of the fALFF maps of $\mathrm{HC}$ and EM at baseline (rsBase) using two-sample $t$ test and then extracted the mean fALFF maps for all subjects and states. The extracted values were converted to normally distributed z-scores to allow for second-level analyses using multilevel modeling one-way repeated measures ANOVA and post hoc Tukey's test. Statistical analysis was performed with the open-source R package (www.Rproject.org).

\section{Positive diametric activity (PDA)}

To further assess the information processing during meditation, we introduce a PDA metric to determine the activation change of CEN and DMN according to their mean fALFF. The PDA metric is based on the hypothesis that there is a causal neural mechanism by which the CEN negatively regulates the $\mathrm{DMN}$ (Chen et al., 2013). This is to say that when CEN activity is increased this produces an inhibitory effect on the DMN and its activity is decreased. Accordingly, we define the PDA as follows:

$$
P D A=\overline{\text { CENfALFF }}-\overline{\text { DMNfALFF, }}
$$

where PDA will always be positive as long as the mean activity of CEN is greater than the mean activity of DMN, reflecting precisely this negative relation between CEN and DMN. Meditation trait differences of the PDA for HC and EM at baseline (rsBase) was assessed using twosample $t$ tests. The PDAs for EM rsBase, Med, and rsPost were analyzed using multilevel modeling one-way repeated measures ANOVA and post hoc Tukey's test.

\section{FC analysis}

FC analysis was performed using a seed-driven approach with in-house, custom software CONN 16.b (Chai et al., 2012; Whitfield-Gabrieli et al., 2012). We performed seed-voxel correlations by estimating maps showing temporal correlations between the BOLD signal from the target ROls and that of every brain voxel (i.e., whole-brain analysis). The specific target ROI clusters were obtained from the previous fALFF analysis two-sample $t$ tests between $\mathrm{HC}$ and EM at rsBase for the DMN and CEN respectively (see above, Brain activity analysis). This yielded seed ROls for the $\mathrm{DMN}$ in the medial prefrontal cortices (see clusters 1 and 2 in Fig. 1Aa and Table 1), which are nodes that have been implicated in processing of self-referential stimuli and in generating a model of the self (Northoff and Bermpohl, 2004) and for the CEN in bilateral inferior frontal gyrus (IFG) and inferior parietal lobule (IPL; see clusters 3, 4, and 5 in Fig. $1 A a$ and Table 1). Physiologic and other spurious sources of noise were estimated and regressed out using the anatomic CompCor method (aCompCor; Chai et al., 2012). Global signal regression, a widely used preprocessing method, was not used because it artificially creates negative cor- 
Table 1. Differences in fractional Amplitude of Low-Frequency Fluctuations (fALFF) for the different meditation states

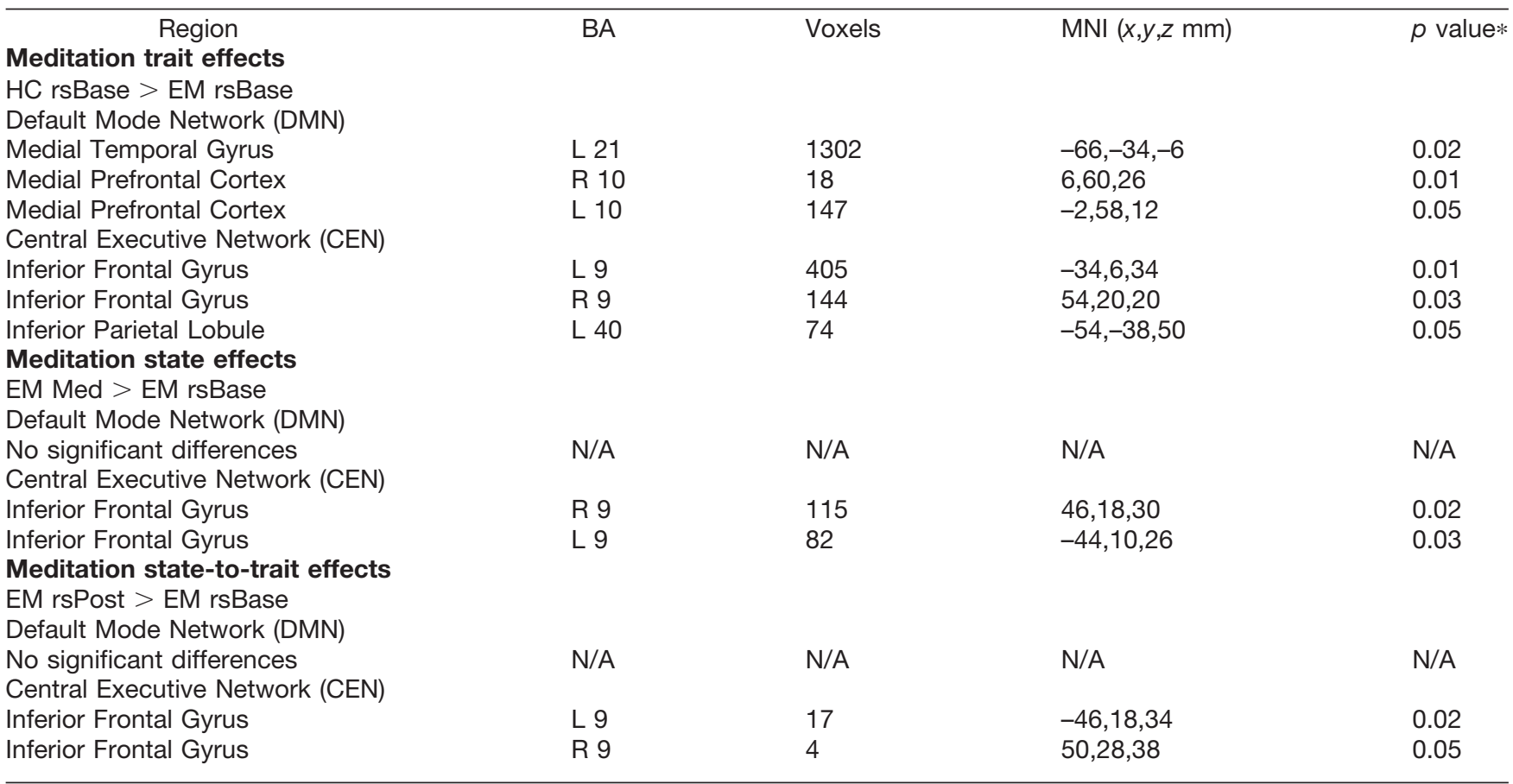

Brodmann areas (BA), number of voxels and Montreal Neurological Institute coordinates (MNI).

*All statistics are nonparametric (5000 permutations) with height threshold $p<0.05$ and cluster-size FDR-corrected $p<0.05$.

relations that prevent the interpretation of anticorrelation (Behzadi et al., 2007; Chai et al., 2012; Whitfield-Gabrieli et al., 2012) and can contribute to group differences in positive correlations (Saad et al., 2012). Instead, aCompCor allows for interpretation of anticorrelations and yields higher specificity and sensitivity compared with global signal regression (Chai et al., 2012). A temporal bandpass filter of 0.008 to $0.09 \mathrm{~Hz}$ was applied simultaneously to all regressors in the model. We used methods that minimize the influence of motion and artifact and that allow for valid identification of correlated and anticorrelated networks (Behzadi et al., 2007; Chai et al., 2012; Whitfield-Gabrieli et al., 2012). To address the spurious correlations in resting-state networks caused by head motion we used quality assurance software artifact detection tools (http:// www.nitrc.org/projects/artifact_detect; http://www.nitrc. org/projects/conn; Whitfield-Gabrieli et al., 2012) to identify problematic time points during the scan. Specifically, an image was defined as an outlier if the head displacement in $x, y$, or $z$ direction was greater than $0.5 \mathrm{~mm}$ from the previous frame, or if the global mean intensity in the image was $>3$ SDs from the mean image intensity for the entire resting scan. A single regressor for each outlier image was included in the first level general linear model along with motion parameters and first order derivatives (there were no significant differences between groups and runs; Fig. 1). The anatomic image for each participant was segmented into white matter, gray matter, and CSF masks using SPM 12. To minimize partial voluming with gray matter, the white matter and CSF masks were eroded by one voxel, which resulted in substantially smaller masks than the original segmentations (Chai et al., 2012). The eroded white matter and CSF masks were then used as noise ROls. Signals from the white matter and CSF noise ROls were extracted from the unsmoothed functional volumes to avoid additional risk of contaminating white matter and CSF signals with gray matter signals. Previous results showed that aCompCor signals were considerably different from the global signal, as regressing higher order principal components of the global signal diminished both positive and negative correlations whereas regressing aCompCor signals resulted in stronger anticorrelations and eliminated spurious correlations (Behzadi et al., 2007). Time series of all the voxels within each seed were averaged, and first-level correlation maps were produced by extracting the residual BOLD time course from each seed and computing Pearson correlation coefficients (CCs) between that time course and the time course of all other voxels. CCs were converted to normally distributed $z$-scores using the Fisher transformation to allow for second-level general linear model analyses. Meditation Trait differences of $\mathrm{HC}$ and EM at baseline (rsBase) were compared using two-sample $t$ tests. Second-level analyses for EM rsBase, Med, and rsPost, were compared using with a one-way repeated measures ANOVA implemented in CONN. All contrasts are nonparametric (1000 permutations) with height threshold $p<0.05$ and cluster-size FDR-corrected $p<0.05$, unless otherwise stated.

\section{Correlation between PDA and FC}

To assess whether there is a relationship between brain activity (fALFF) and FC, we correlated the individual PDA scores (see above) with differences in FC of DMN and CEN ROls for the different meditation states. 

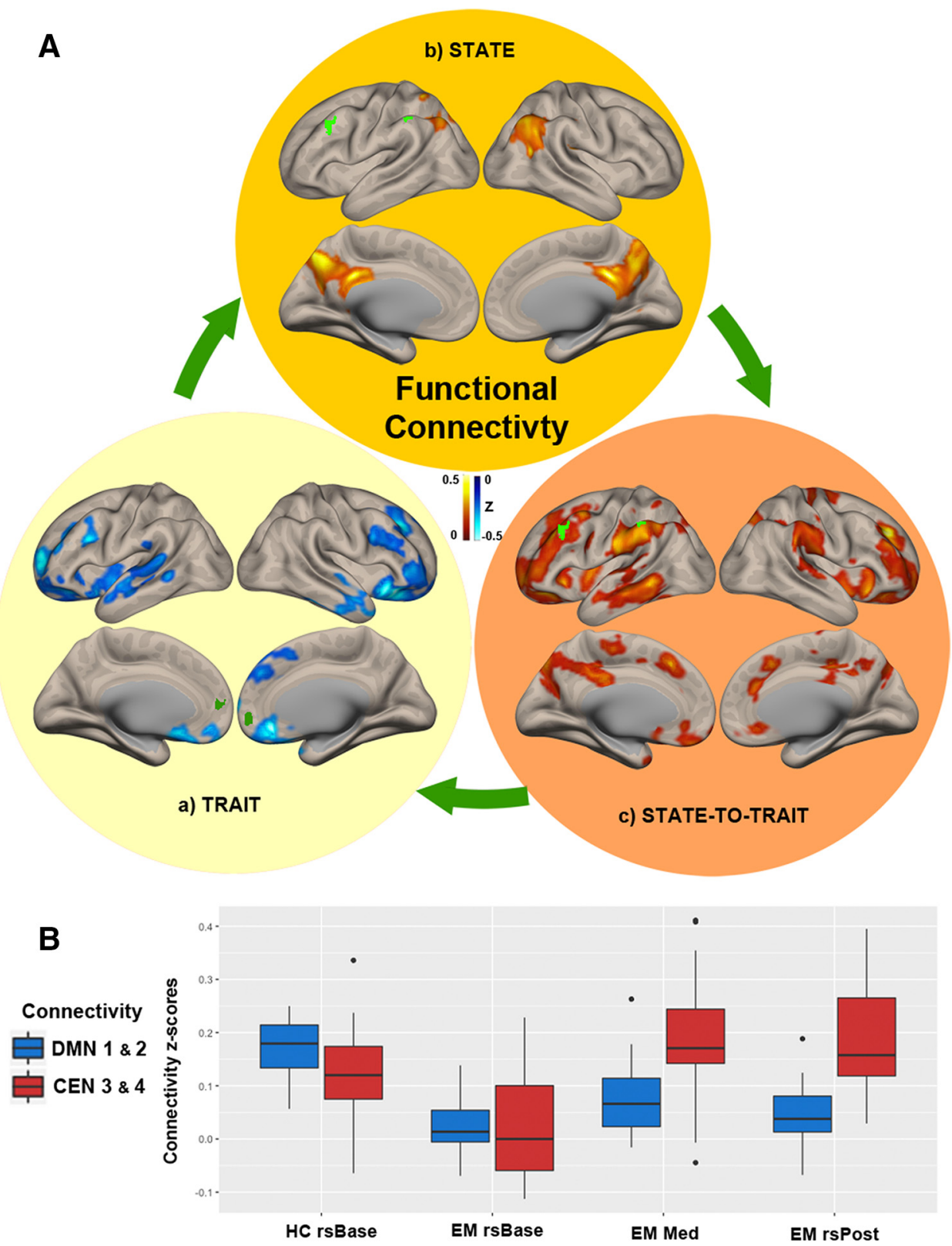

C

Contrasts

a) TRAIT

b) STATE

c) STATE TO TRAIT

HC rsBase < EM rsBase

$\begin{array}{ccc}\text { EM rsBase } & <\text { EM Med } & \\ \text { EM rsBase } & < & \text { EM rsPost }\end{array}$

Figure 2. State-to-trait meditation functional connectivity (FC) changes. Aa, Brain regions showing trait FC changes between experienced meditators (EM) and healthy controls $(\mathrm{HCs})$ at baseline ( $\mathrm{HC}$ rsBase $<\mathrm{EM}$ rsBase). $\boldsymbol{A} \boldsymbol{b}$, Brain regions that show significant FC changes during the meditation state in meditators (EM rsBase $<$ EM Med). Ac, Brain regions that show significant FC changes during the transition from state-to-trait meditation in meditators (EM rsBase $<$ EM rsPost). Dark green (DMN ROls 1 and 2$)$ and light green (CEN ROls 3 and 4) clusters show in each case the seeds used to determine the shown contrast (Fig. 1Aa). B, Boxplot showing mean FC z-scores in blue (DMNs 1 and 2) and red (CENs 3 and 4) during baseline (rsBase), meditation (Med), and post-meditation (rsPost) for HCs and EMs. C, Schematic representation of state-to-trait contrasts. All stats shown are nonparametric (1000 permutations) with height threshold $p<0.05$ and cluster-size FDR-corrected $p<0.05$. Black dots represent subjects that lie beyond the whiskers. 
Table 2. Differences in functional connectivity (FC) for the different meditation states

\begin{tabular}{|c|c|c|c|c|c|}
\hline $\begin{array}{l}\text { Region } \\
\text { Meditation trait effects } \\
\text { EM rsBase > HC rsBase } \\
\text { Default Mode Network (DMN) }\end{array}$ & Connectivity & BA & Voxels & $\mathrm{MNI}(x, y, z \mathrm{~mm})$ & $p$ value* \\
\hline Superior Frontal Gyrus & Reduced & L 11 & $>1000$ & $-16,60,26$ & 0.01 \\
\hline Middle Frontal Gyrus & Reduced & L 9 & $>200$ & $-26,26,32$ & 0.01 \\
\hline Inferior Parietal Lobule & Reduced & L 40 & $>200$ & $-38,-48,26$ & 0.02 \\
\hline $\begin{array}{l}\text { Superior Temporal Gyrus } \\
\text { Central Executive Network (CEN) }\end{array}$ & Reduced & R 38 & $>200$ & $48,16,-20$ & 0.03 \\
\hline $\begin{array}{l}\text { No significant differences } \\
\text { Meditation state effects } \\
\text { EM Med > EM rsBase } \\
\text { Default Mode Network (DMN) }\end{array}$ & $\mathrm{N} / \mathrm{A}$ & $\mathrm{N} / \mathrm{A}$ & N/A & $\mathrm{N} / \mathrm{A}$ & $\mathrm{N} / \mathrm{A}$ \\
\hline $\begin{array}{l}\text { No significant differences } \\
\text { Central Executive Network (CEN) }\end{array}$ & N/A & $\mathrm{N} / \mathrm{A}$ & $\mathrm{N} / \mathrm{A}$ & $\mathrm{N} / \mathrm{A}$ & $\mathrm{N} / \mathrm{A}$ \\
\hline Middle frontal gyrus & Increased & $\mathrm{L} 10$ & $>200$ & $-29,48,15$ & 0.02 \\
\hline Middle frontal gyrus & Increased & $\mathrm{R} 10$ & $>200$ & $31,52,12$ & 0.02 \\
\hline Anterior cingulate cortex & Increased & L 32 & $>200$ & $4,30,24$ & 0.02 \\
\hline Posterior cingulate cortex & Increased & R 31 & $>200$ & $3,-31,38$ & 0.03 \\
\hline $\begin{array}{l}\text { Inferior Parietal Lobule } \\
\text { State-to-trait effects } \\
\text { EM rsPost > EM rsBase } \\
\text { Default Mode Network (DMN) }\end{array}$ & Increased & L 40 & $>200$ & $-38,-46,46$ & 0.03 \\
\hline $\begin{array}{l}\text { No significant differences } \\
\text { Central Executive Network (CEN) }\end{array}$ & $\mathrm{N} / \mathrm{A}$ & $\mathrm{N} / \mathrm{A}$ & N/A & $\mathrm{N} / \mathrm{A}$ & $\mathrm{N} / \mathrm{A}$ \\
\hline Precuneus & Increased & L 23 & $>1000$ & $-2,-42,28$ & 0.02 \\
\hline Angular gyrus & Increased & R 39 & $>1000$ & $50,-66,33$ & 0.02 \\
\hline
\end{tabular}

Brodmann areas (BA), number of voxels and Montreal Neurological Coordinates (MIN).

*nonparametric (1000 permutations) with height threshold $p<0.05$ and cluster-size FDR-corrected $p<0.05$.

\section{Results}

\section{Meditation trait effects}

fALFF analysis

$D M N$ EM showed reduced activity in the left medial temporal gyrus (MTG; BA 21), right superior frontal gyrus (SFG; BA 6), left MPFC; BA 10, Fig. 1Aa1,Aa2, blue box plots in Fig. $1 B$ (HC rsBase < EM rsBase) rs Base and Table 1.

CEN EM showed reduced activity in bilateral DLPFC; BA 9, Fig. 1Aa3,Aa4; red box plots ( $\mathrm{HC}$ rsBase < EM rsBase) in Fig. 1B; Table 1 and left IPL (BA 40, Fig. 1Aa5; Table 1). For this and all other fALFF significant MNI coordinates, see Table 1.

\section{FC analysis}

$D M N$ EM showed reduced connectivity with left SFG (BA 11), right medial frontal gyrus (MFG; BA 10), IPL (BA 40), and superior temporal gyrus (STG; BA 38), Fig. 2Aa; blue box plots ( $\mathrm{HC}$ rsBase < EM rsBase) in Fig. $2 B$ and Table 2. For this and all other significant connectivity coordinates, see Table 2.

CEN No differences were found.

$P D A$ analysis

No significant differences were found.

Correlations between PDA and FC

$D M N$ No significant correlations were found.

CEN No significant correlations were found.

Correlations between hours of meditation practice and FC $D M N$ No significant correlations were found.
CEN Whole-brain FC analysis revealed a significant correlation $(R=0.87)$ between the hours of meditation practice and connectivity between CEN and MPFC at rsBase for EM (Fig. 4A).

To better understand this positive correlation between meditation experience and increased connectivity between CEN and MPFC, which also has been reported in other studies comparing novice versus expert meditators (Brewer et al., 2011; Jang et al., 2011; Shaurya Prakash et al., 2013), we divided our EM group into two sub-groups (median = $1130 \mathrm{~h})$ : EMs with $>1130 \mathrm{~h}$ of daily practice $(\mathrm{EM}>1130$; approximately three years) and intermediate meditators (EM $<1130$ ) and conducted a multilevel modeling one-way repeated measures ANOVA and post hoc Tukey's test for the connectivity $z$-scores between CEN and MPFC. The results confirmed a significant difference between $\mathrm{HC}$ (mean = 0.13 ) and $\mathrm{EM}<1130$ (mean $=-0.04, \mathrm{~b}=-0.16, p<1 \mathrm{e}-3)$ but no difference between $\mathrm{HC}$ and $\mathrm{EM}>1130$ (mean $=0.04$, $b=-0.09, p=0.08$ ). Furthermore, there was also a significant difference between EM $<1130$ (median $=-0.25$ ) and EM $>$ 1130 (median $=-0.07, \mathrm{~b}=0.17, p=0.04$; Fig. 2).

Correlations between hours of meditation practice and PDA

No significant correlations were found for meditation trait, state, or state-to-trait PDA and meditation hours.

\section{Meditation state effects \\ fALFF analysis \\ $D M N$ No significant differences were found. \\ CEN The multilevel modeling one-way repeated mea- sures ANOVA yielded significant variation among rsBase,}



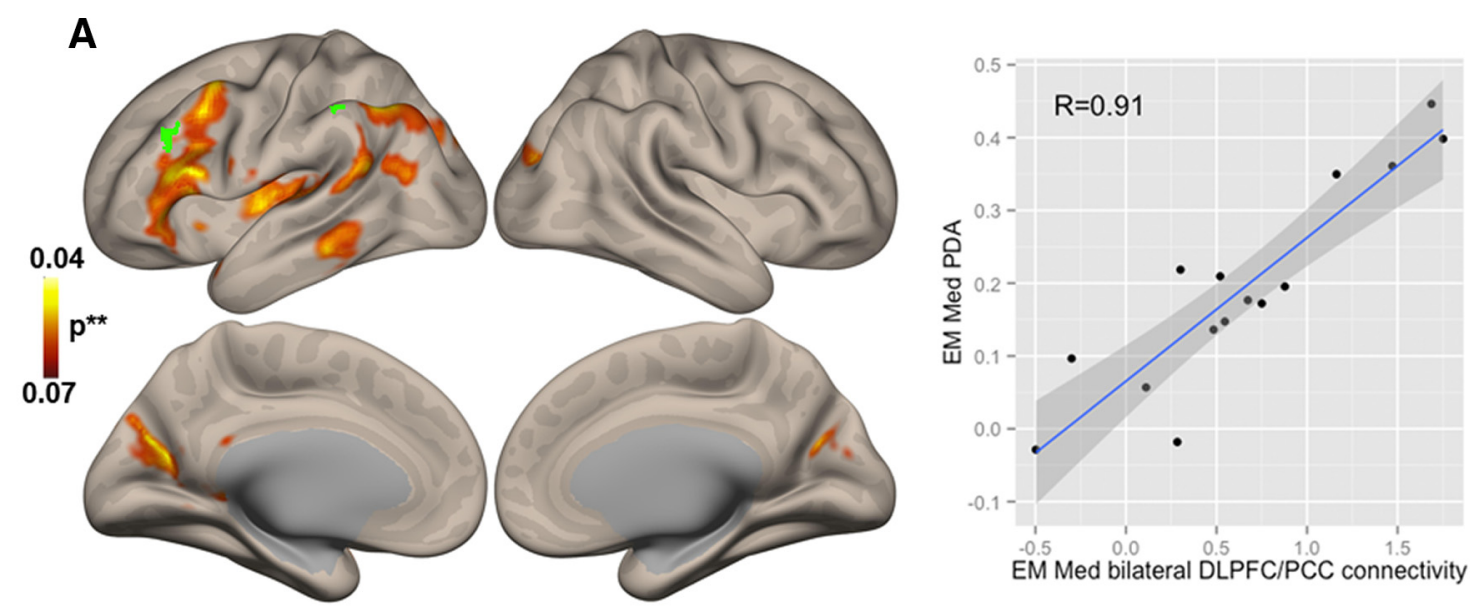

B
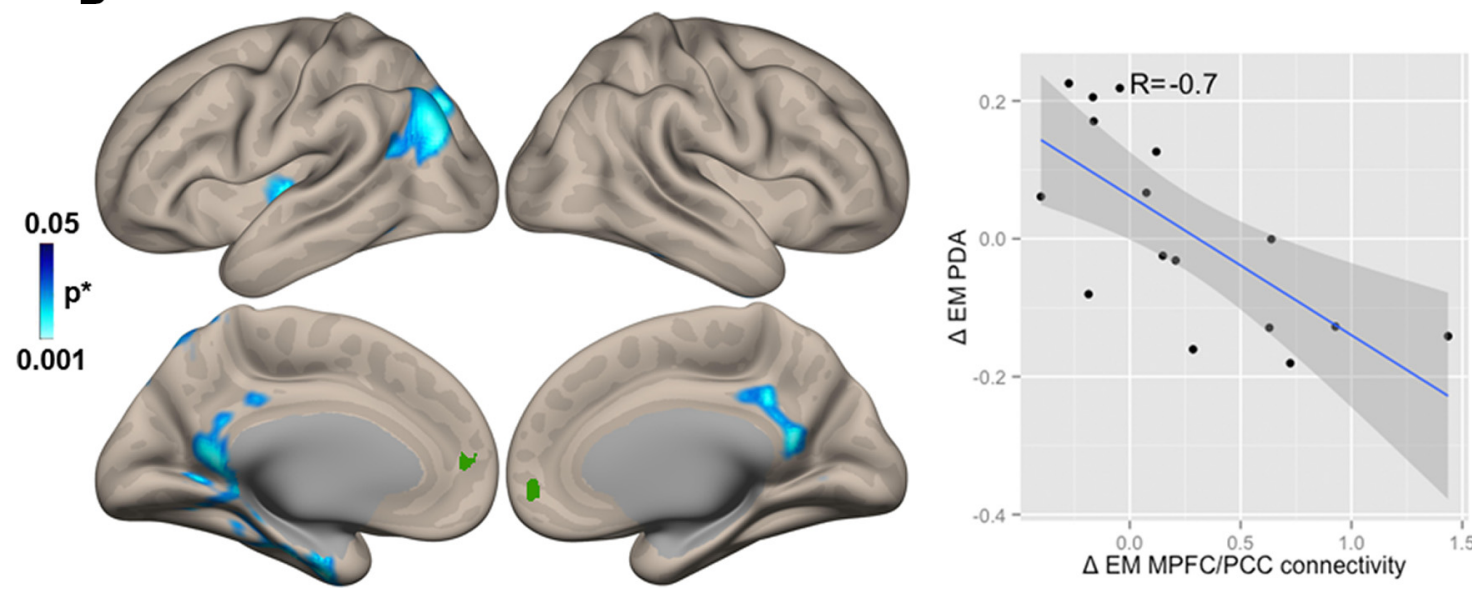

Figure 3. Correlations between Positive Diametric Activity (PDA) and Functional Connectivity (FC). $\boldsymbol{A}$, Brain regions that show significant correlation between PDA and FC during the meditation state in experienced meditators (EM) (EM Med). $\boldsymbol{B}$, Brain regions that show significant correlation between the change in PDA and change in FC during the transition from state-to-trait meditation $(\Delta \mathrm{EM}=$ rsBase - rsPost). Dark green clusters at the Default Mode Network (DMN ROls 1 and 2 from Fig. $1 \mathrm{Aa}$ ) and bright green clusters at the Central Executive Network (CEN ROls 3 and 4 from Fig. 1Aa) show in each case the seeds used to determine the estimated contrast. *nonparametric (1000 permutations) with height threshold $p<0.05$ and cluster-size FDR-corrected $p<0.05 ; * *$ parametric stats with height threshold $p<0.05$ and cluster-size FDR-corrected $p<0.05$.

Med, and rsPost, $\chi^{2}(2)=24.57, p<1 \mathrm{e}-04$. The post hoc analysis showed that CEN fALFF was significantly increased in bilateral DLPFC (BA 9, Fig. 1Ab) during Med (mean $=0.3)$ compared to rsBase (mean $=-0.55, \mathrm{~b}=$ $0.84, p<1 \mathrm{e}-04)$. See red box plots (EM rsBase $<$ Med) in Figure $1 B$.

\section{FC analysis}

$D M N$ No significant differences were found.

CEN EM showed increased connectivity of posterior cingulate cortex (PCC; BA 31) and IPL; BA 40; Fig. 2Ab and red box plot (EM rsBase < Med) of Fig. $2 B$.

\section{$P D A$ analysis}

The multilevel modeling one-way repeated measures ANOVA yielded that there was significant variation among rsBase, Med, and rsPost, $\chi^{2}(2)=12.54, p=0.005$. The post hoc analysis showed that PDA was significantly increased during Med (mean $=0.65$ ) compared to rsBase (mean $=0.23, \mathrm{~b}=0.57, p<0.003)$ and rsPost (mean $=$
$0.36, \mathrm{~b}=0.42, p<0.02$ ). See green box plots (EM rsBase $<$ Med) in Figure $1 B$.

\section{Correlations between PDA and FC}

$D M N$ No significant correlations were found.

CEN There was positive correlation $(R=0.91$, parametric stats with height threshold $p<0.05$ and clustersize FDR-corrected $p<0.05$ ) between PDA during Med and FC during Med of bilateral DLPFC (BA 9) and left posterior cingulate cortex (PCC; BA 31), left IFG (BA 45), left STG (BA 22), and left inferior parietal lobe (IPL; BA 40; Fig. $3 A$ ). For this and all other significant correlation analysis coordinates, see Table 3 .

\section{Correlations between hours of meditation practice and FC}

$D M N$ Whole-brain FC analysis showed a significant correlation ( $R=0.87$ ) between the hours of meditation and the increase in connectivity between rDLPFC and MPFC during meditation (Fig. 4B). 
Table 3. Correlation between Positive Diametric Activity (PDA) and Functional Connectivity (FC) in experienced meditators (EM)

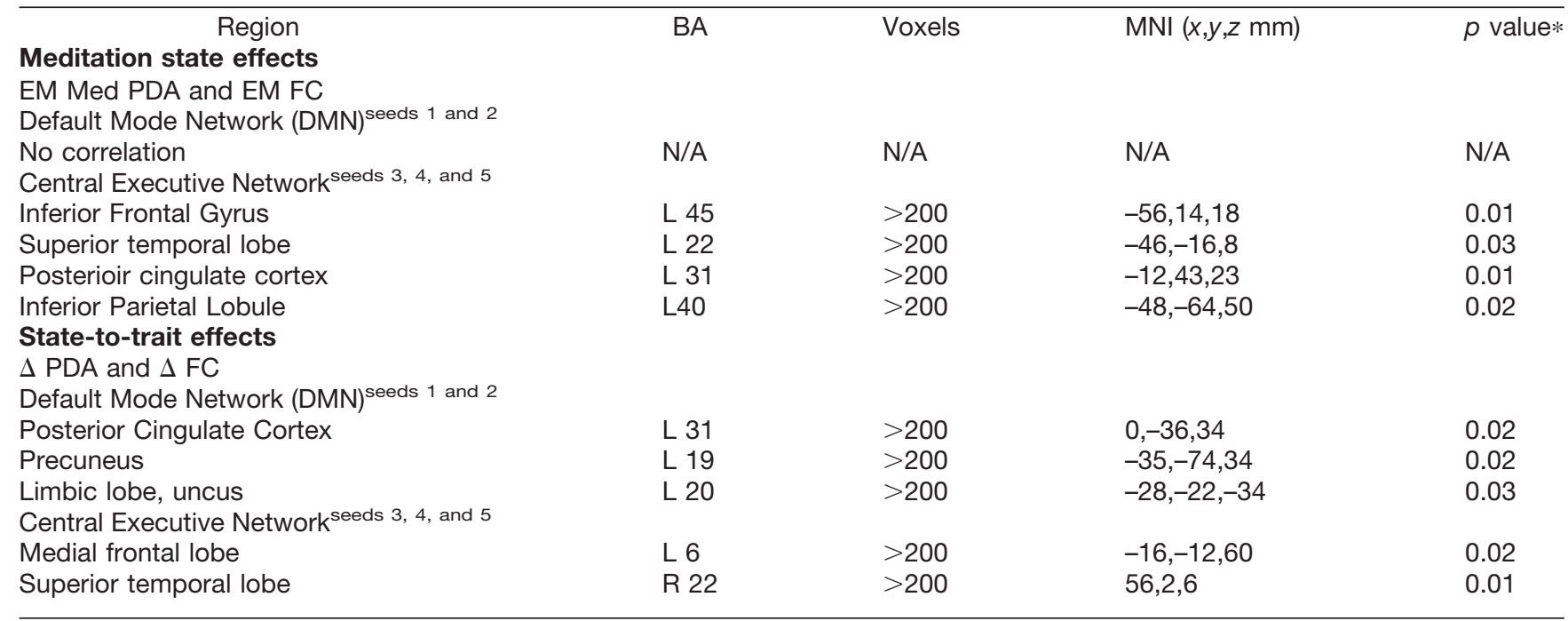

ROIs 1,2,3,4 and 5 from Fig. $1 A a$.

*nonparametric (1000 permutations) with height threshold $p<0.05$ and cluster-size FDR-corrected $p<0.05$.

CEN No significant correlations were found.

\section{Correlations between hours of meditation practice and PDA}

No significant correlations were found for meditation trait, state, or state-to-trait PDA and meditation hours.

\section{Meditation state-to-trait effects \\ fALFF analysis}

$D M N$ No significant differences were found.

CEN The multilevel modeling one-way repeated measures ANOVA yielded that there was significant variation among rsBase, Med, and rsPost, $\chi^{2}(2)=24.57, p<$ 1e-04. The post hoc analysis showed that CEN fALFF was significantly increased in bilateral DLPFC (BA 9, Fig. 1Ac) during rsPost (mean $=0.09$ ) compared to rsBase; mean $=-0.55, \mathrm{~b}=0.63, p=0.006$; red box plots (EM rsBase $<$ EM rsPost) in Fig. $1 B$.

FC analysis

$D M N$ No differences were found.

CEN EM showed increased connectivity $\left(\chi^{2}(2)=\right.$ 14.47, $p<0.001$ ) with the Precuneus (BA 23) and right angular gyrus (BA 39) at rsPost compared to rsBase; Fig. $2 A c$ and red box plots (EM rsBase < EM rsPost) of Fig. $2 B$.

\section{$P D A$ analysis}

PDA The multilevel modeling one-way repeated measures ANOVA yielded no significant differences. However a two-sample paired $t$ test showed a significant increase relative to rsBase; $t_{(15)}=1.97, p=0.03$, green box plots (EM rsBase < EM rsPost) of Fig. 1B, uncorrected.

\section{Correlations between PDA and FC}

$D M N$ There was a significant negative correlation $(R=$ -0.70) between the change in PDA from rsBase to rsPost and the change in $\mathrm{FC}$ from rsBase to rsPost between MPFC (BA 10) and posterior cingulate cortex (PCC; BA 31), precuneus (BA 19), and limbic lobe (BA 20; Fig. 3B).
Correlations between hours of meditation practice and FC $D M N$ No significant correlations were found.

CEN Whole-brain FC analysis showed a significant correlation $(R=0.63)$ between the change in CEN and PCC connectivity from rsBase to rsPost and the hours of meditation practice (Fig. 4C).

\section{Correlations between hours of meditation practice and} PDA

No significant correlations were found for meditation trait, state, or state-to-trait PDA and meditation hours. For this and all other significant correlation analysis coordinates, see Table 4.

\section{Discussion}

Meditation trait was characterized by a significant reduction in activity and FC within the DMN and increased anticorrelations between DMN and CEN in EMs. However, the latter anticorrelations were only present in meditators with less than three years of practice. Conversely, the meditation state and the meditation state-to-trait periods showed increased activity and FC within the DMN and between DMN and CEN. While there were no meditation trait PDA metric differences, we found significant increase during meditation state that persisted in meditation stateto-trait. The gradual reconfiguration in DMN and CEN suggest a neural mechanism by which the CEN negatively regulates the DMN and is probably responsible for the long-term trait changes seen in meditators and reported psychological well-being.

To our knowledge, no previous study has directly compared trait, state, and state-to trait conditions in EMs using fALFF and FC. In so doing, our findings demonstrate the following for each stage.

\section{Meditation trait}

We found that meditation trait is characterized by (1) a significant reduction in brain activity of specific nodes of the DMN, most prominently the MPFC and MTG as well 

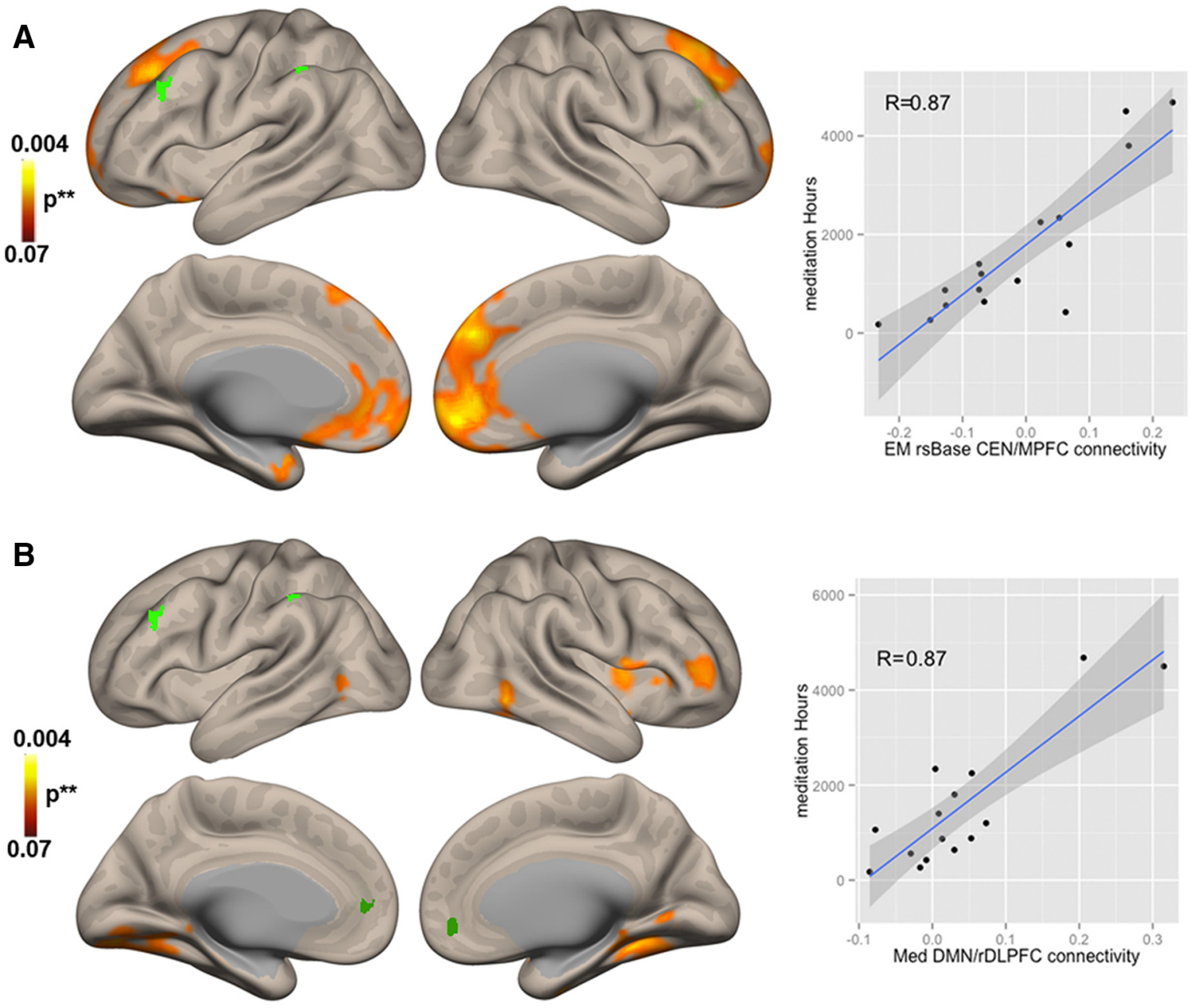

EM rsBase CEN/MPFC connectivity
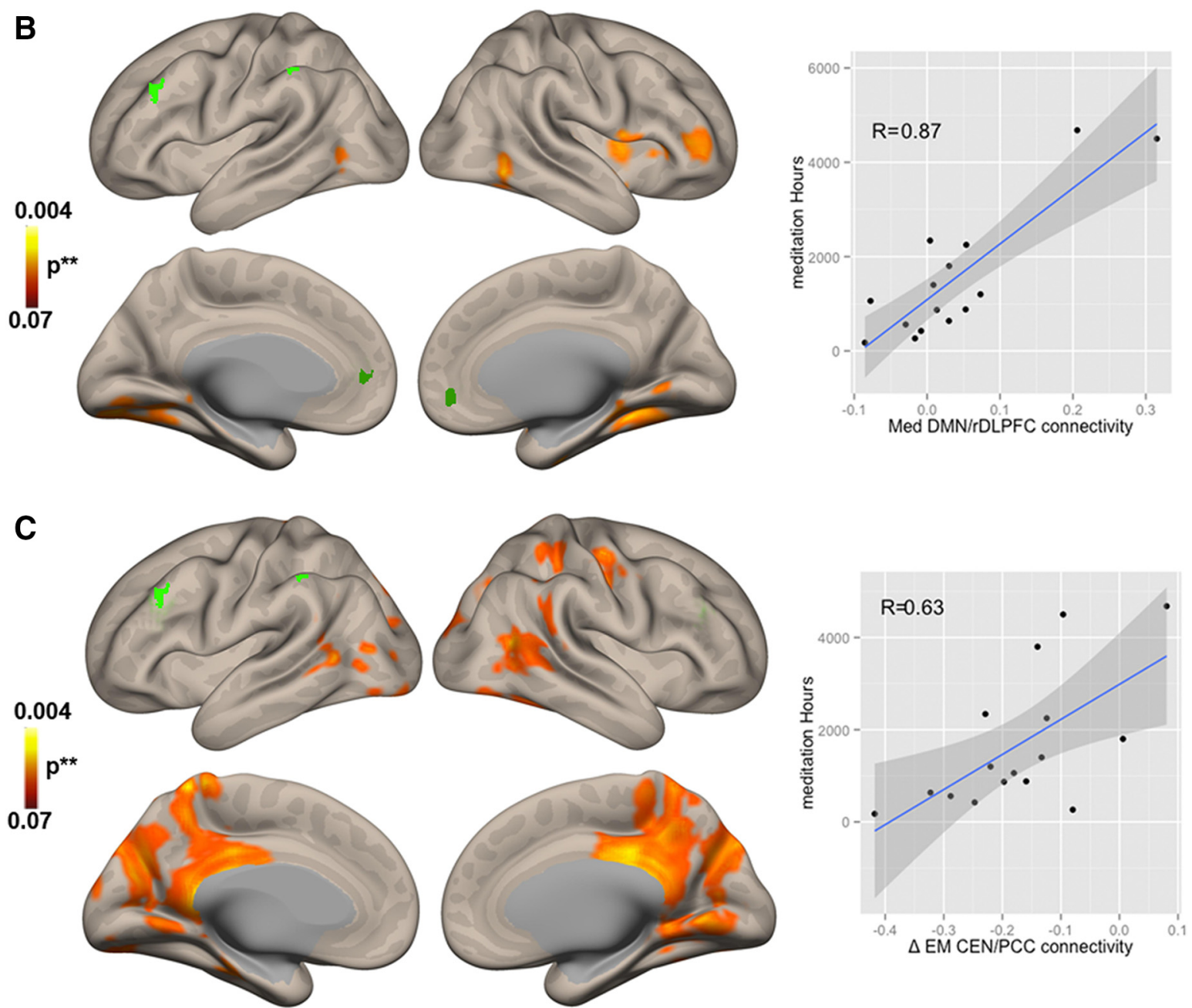

Figure 4. Correlations between meditation hours (MedHrs) and functional connectivity (FC). $\boldsymbol{A}$, Brain regions showing the correlation of MedHrs and FC at baseline for meditators. $\boldsymbol{B}$, Brain regions that show significant correlation between MedHrs and FC during the meditation state in meditators (EM Med). $\boldsymbol{C}$, Brain regions that show significant correlation between MedHrs and the change in FC during the transition from state-to-trait meditation in meditators ( $\Delta \mathrm{EM}=$ rsBase - rsPost). Dark green clusters at the Default Mode Network (DMN ROls 1 and 2 from Fig. 1Aa) and bright green clusters at the Central Executive Network (CEN ROIs 3 and 4 from Fig. $1 \mathrm{Aa}$ ) show in each case the seeds used to determine the estimated contrast. **nonparametric (1000 permutations) with height threshold $p<0.05$ and cluster-size FDR-corrected $p<0.05$. 
Table 4. Correlation between meditation hours and Functional Connectivity (FC) in experienced meditators (EM)

\begin{tabular}{|c|c|c|c|c|c|}
\hline Region & $R$ & BA & Voxels & MNI $(x, y, z \mathrm{~mm})$ & $p$ value \\
\hline $\begin{array}{l}\text { Meditation state effects } \\
\text { Default Mode Network (DMN) }\end{array}$ & & & & & \\
\hline $\begin{array}{l}\text { Middle frontal gyrus } \\
\text { Central Executive Network (CEN) }{ }^{\text {seeds } 3,4, \text { and } 5}\end{array}$ & 0.87 & R 10 & $>200$ & $45,44,12$ & 0.02 \\
\hline $\begin{array}{l}\text { No correlations } \\
\text { State-to-trait effects }\end{array}$ & $\mathrm{N} / \mathrm{A}$ & $\mathrm{N} / \mathrm{A}$ & $\mathrm{N} / \mathrm{A}$ & $\mathrm{N} / \mathrm{A}$ & $\mathrm{N} / \mathrm{A}$ \\
\hline $\begin{array}{l}\text { Default Mode Network (DMN) })^{\text {seeds } 1 \text { and } 2} \\
\text { No correlations } \\
\text { Central Executive Network (CEN) })^{\text {seeds } 3,4 \text {, and } 5}\end{array}$ & N/A & N/A & $\mathrm{N} / \mathrm{A}$ & $\mathrm{N} / \mathrm{A}$ & $\mathrm{N} / \mathrm{A}$ \\
\hline $\begin{array}{l}\text { Posterior Cingulate Cortex } \\
\text { Trait effects } \\
\text { Default Mode Network (DMN) })^{\text {seeds } 1 \text { and } 2}\end{array}$ & 0.63 & L 29 & $>200$ & $-06,-44,14$ & 0.03 \\
\hline $\begin{array}{l}\text { No correlations } \\
\text { Central Executive Network (CEN) })^{\text {seeds } 3,4 \text {, and } 5}\end{array}$ & $\mathrm{~N} / \mathrm{A}$ & $\mathrm{N} / \mathrm{A}$ & $\mathrm{N} / \mathrm{A}$ & $\mathrm{N} / \mathrm{A}$ & $\mathrm{N} / \mathrm{A}$ \\
\hline Medial Frontal Gyrus & 0.87 & L 10 & $>200$ & $-06,44,8$ & 0.01 \\
\hline
\end{tabular}

ROls 1,2,3,4 and 5 from Fig. $1 A a$.

*nonparametric (1000 permutations) with height threshold $p<0.05$ and cluster-size FDR-corrected $p<0.05$.

as CEN nodes in the right and left DLPFC and (2) a reduction in FC, both within DMN and between DMN and CEN. Thus, the former reduction in intrinsic DMN connectivity would speak for trait reduced synchrony of DMN regions for meditators and is in accordance with previous studies (Hasenkamp and Barsalou, 2012; Doll et al., 2015) which found that a region in MPFC showed decreased connectivity with the PCC in mindfulness experts compared to novices. Similarly, the latter finding of reduced FC between DMN and CEN for meditators in the baseline resting state is in accordance with two recent studies (Doll et al., 2015; Kemmer et al., 2015), suggesting a critical interplay between DMN and CEN for repeated engagement of attention on present moment experience. Hence, DMN activity and FC, instead of being engaged in taskunrelated thought or mind-wandering, resulting in activation and synchronization of the DMN (Mason et al., 2007), rather is again and again suppressed to re-engage in present moment awareness and hence reflects the stronger anti-correlated coupling between CEN and DMN (Mooneyham et al., 2017; Marusak et al., 2018). This is idea is in accordance with preliminary analysis using dynamic FC on the meditation state data that suggest that meditation trait is characterized by more transitions between brain states (mindful vs mind-wandering) over time, and thus meditators probably spent overall less time in a mind-wandering or a mindless state (Martínez et al., 2019). However, and most importantly, the additional finding of a positive correlation between meditation experience and increased connectivity between CEN and MPFC, which also has been reported in other studies comparing novice versus expert meditators (Brewer et al., 2011; Jang et al., 2011; Shaurya Prakash et al., 2013) and, which at first seems to contradict the increase in anticorrelations for meditators in general, rather is a subtle difference that points to additional network reconfiguration occurring as practice increases for expert meditators (Brewer et al., 2011; Hasenkamp and Barsalou, 2012). We then disentangled this finding by searching for the differences between intermediate $(<1130 \mathrm{~h}$ of practice, approximately three years of $1 \mathrm{~h}$ daily practice) and more
EMs $(>1130$ h) FC in these nodes. The finding, hence suggests that the trait state of intermediate meditators is characterized by a stronger reduction in DMN connectivity and significant increases in anticorrelations between CEN and MPFC. In more EMs ( $>1130 \mathrm{~h}$ of practice) the reduction in DMN connectivity still remains, however the anticorrelations have returned to a pre-meditation state. This finding, we think, is of major importance and points to the evolution of brain activity and connectivity changes as meditation progresses from an intermediate to more advanced stages, and that this change is rather a slow one, with the final sole reduction of DMN activity and connectivity independent of CEN suppression of at least three years of practice and can even evolve to a sustained increase in connectivity between CEN and DMN in meditators with more than three years of experience (Brewer et al., 2011; Creswell et al., 2016). Additionally, we think that this trait suppression of DMN in more EMs independent of anticorrelations with the CEN, is the ultimate network reconfiguration without any active and repeated suppression of the DMN by the CEN and thus, a more effective, consolidated effortless baseline, reflecting a completely transformed and stable mindful state with suppression of DMN without the more active and repeated transitions between mindful versus mindwandering brain states in intermediate meditators. However, this hypothesis has to be tested in longitudinal studies.

\section{Meditation state}

We found that meditation state is characterized by the following: (1) increase in the activity of specific CEN nodes (bilateral DLPFC), (2) increased FC between CEN nodes and DMN nodes (MPFC and PCC), (3) increased PDA, (4) PDA positively correlates with the strength in FC between the CEN and the DMN, and (5) that meditation experience (meditation hours) positively correlates with connectivity between MPFC and right DLPFC during meditation. These findings are in accordance with previous literature (Brewer et al., 2011; Hasenkamp and Barsalou, 2012) and suggest that the neural mechanisms underlying the active 
meditation state is associated with differential activation and connectivity of CEN nodes modulate activity and connectivity of the DMN. Importantly, although we cannot rule out that other brain networks mediate the effect of CEN on the DMN, our results indicate that activity in the CEN, specifically in the DLPFC effects on the activity and connectivity of the DMN hub nodes, i.e., MPFC and PCC. This hypothesis is in line with previous meditation studies (Brewer et al., 2011; Hasenkamp and Barsalou, 2012; Hasenkamp et al., 2012) but is of particularly interest given a study by Chen et al. (2013), where they used TMS and $\mathrm{AMRI}$ to demonstrate a directional causal relationship by which a DLPFC node situated within the CEN inhibits the MPFC portion of the DMN. This in turn is further supported by evidence of monosynaptic projections between CEN and DMN structures in rhesus monkeys, which indicate that these efferent pathways are part of an elaborate anatomic circuit which could mediate aspects of attention, memory, and external or internal perception (Selemon and Goldman-Rakic, 1988). What is more, recent evidence has shown that there is a direct relation between GABAergic inhibition within the MPFC and the reactivity of amygdala during emotional processing. Delli Pizzi et al. (2017) investigated the mPFC-amygdala circuit both with resting-state fMRI (rs-fMRI) and proton MR spectroscopy (MRS) as well as trait anxiety. Their results showed that the rs-fMRI signals of the amygdala and the mPFC were significantly anti-correlated and that this negative functional coupling between the two regions was inversely correlated with the GABA+/tCr level within the MPFC and the STAI-Y2 scores. This suggests a close relationship between MPFC GABA levels and functional interactions within the MPFC-amygdala circuit. Although this is still an open question and needs additional research with simultaneous MRS acquisition during and after meditation, we propose that a meditation state: (1) increases activity within the CEN, (2) this increase in CEN activity directly downregulates the two major DMN nodes (i.e., MPFC and PCC), (3) this down regulation of MPFC is coupled with a reduction in GABA+/tCr levels and reduced amygdala reactivity which, and (4) have a direct impact on anxiety scores and the physiology of emotion regulation.

\section{Meditation state-to-trait}

We found that the meditation state-to-trait is characterized by shoeing remnants of the meditation state effect both in activity and connectivity. Specifically, (1) increased activity of the CEN; (2) increased FC between CEN nodes and DMN, although only with the PCC, which has been suggested to be more related to internal meditation practices (Scheibner et al., 2017); and (3) an increased PDA. Moreover, the change in PDA from rsBase to rsPost was negatively correlated with change in intrinsic connectivity of the DMN (MPFC and PCC), i.e., the greater the increase in PDA the less the intrinsic connectivity of the DMN at rsPost. This is also in line with previous studies that suggest that the post-task restingstate network activity and connectivity reflect an aspect of the immediately preceding brain state (Waites et al., 2005) and that these brain changes support the role of learning from a recently performed task as a concomitant process in expertise development (Muraskin et al., 2016). Hence, it further supports the hypothesis that the activity within CEN nodes (specifically DLPFC) actively suppresses $\mathrm{DMN}$ nodes and that this suppression carries over during a restful state after meditation, although it shifts to a more posterior node, namely the PCC, probably because this node is more engaged in this particular type of meditation, i.e., internal focused meditation (Scheibner et al., 2017). Finally, we found that meditation experience positively correlates with change in CEN-DMN connectivity. Hence, the more EMs seem to have a larger homeostatic rebound after meditation in CEN-DMN connectivity (for a discussion of this hypothesis, see below).

Finally, and because of the design of the present study, we propose that both, the increased PDA as well as the increased connectivity between DMN and CEN during meditation, as well as the remnants after meditation, at the beginning of practice, effectively produce a "homeostatic rebound" to what we identify as the meditation trait, namely the reduced activity and connectivity within DMN and between DMN and CEN. We think that brain activity, brain connectivity and long-term ensurance of homeostasis depend on intrinsic properties that determine the functionality of these neuronal networks. Homeostatic factors are inherently important and involve complex self-regulatory mechanisms (Davis, 2013). Consequently, it seems reasonable to view this homeostatic rebound as the plasticity that results from a repeated meditation practice within a context of otherwise stable network configurations. First, without the existence of potent mechanisms that perturb this normal balance between networks, and secondly, similarly potent mechanisms that in turn stabilize this perturbation, our capacity to learn and change brain function would be lost. Hence, we suggest, that there is a two stage reconfiguration or homeostatic plasticity (Davis, 2013; Hellyer et al., 2017), that evolves with meditation practice. First, as meditation practice begins, it produces stronger anticorrelated coupling between CEN and DMN (Mooneyham et al., 2017; Marusak et al., 2018) and thus increases the frequency of repeated periods of DMN suppression, even without being actively engaged in meditation, resulting in increased number of moments during the day of engagement in present moment awareness and less mindlessness. This initial change is in accordance with additional evidence showing that increased anticorrelations between $\mathrm{DMN}$ and CEN are associated with a healthy development (Chai et al., 2014) and aging (Keller et al., 2015; Esposito et al., 2018), cognitive reserve (Franzmeier et al., 2017), superior cognitive performance (Chai et al., 2014), reduced risk of psychopathology (Whitfield-Gabrieli et al., 2009; Andrews-Hanna et al., 2014), increased emotional stability (Servaas et al., 2017), and overall physiologic and psychological well-being (Fountain-Zaragoza and Prakash, 2017). As meditation increases, a second reconfiguration occurs where the frequency of repeated periods of DMN suppression start to overlap and rather become prolonged periods of engagement in present moment awareness up until the point where it is just continued present moment awareness. Once this 
point has been reached, we think that there is no more need of active monitoring if one is in a mindless state or mindful state and thus the anticorrelations start to return to a normal pre-meditation level.

The plasticity resulting from a repeated meditation practice, i.e., the suggested homeostatic rebound, may also be the underlying mechanism of many of the benefits reported with meditation practice (Goldberg et al., 2018) that depend on the top-down regulation of the DMN by CEN (Chen et al., 2013; Garrison et al., 2015). In doing so, it is possible that functional abnormalities in cortical and subcortical regions involved in emotion regulation such as anxiety, depression, or other types of psychopathology that relate to deficiencies in noradrenergic and serotonergic function are also recalibrated and thus enhancing brain noradrenergic or serotonergic transmission (Whitfield-Gabrieli and Ford, 2012; Willner et al., 2013). Meditation training, thus, with time, may lead to observable changes in the brain and in neurotransmitter levels (Guglietti et al., 2013; Jindal et al., 2013) accounting for its antidepressant effects and use in psychotherapy. However, this last hypothesis has to be corroborated with further studies that particularly look at this process.

We also want to note some limitations of this study. First off, when we talk about "activity" in the present study we do this with complete knowledge of the limitations of BOLD imaging as the standard technique used to generate images in $\mathrm{fMRI}$ studies, and that relies on regional differences in cerebral blood flow to indirectly delineate regional activity (Arthurs and Boniface, 2002; Huettel, 2004). Thus, activity in the present study refers to BOLD activity. There were a modest number of participants. In turn, this motivated a ROI approach focused on specific nodes from the DMN and CEN, based on the prior literature, so that a conservative level of statistics could be employed. A strength of this study is that it represents a first step in elucidating the potential neurobehavioral mechanisms mediating the practice of meditation on DMN activity and the FC. Specifically, it suggests that homeostatic rebound of anticorrelated DMN and CEN networks after meditation could be the compensatory mechanisms operating in the brain that may account for the trait changes in meditators.

\section{Conclusion}

Here, we examined the brain changes underlying the state-to-trait experience and training of meditation. We focused on the activity and connectivity of the default and executive networks given their respective roles in internal cognition, self-regulation, and awareness. The findings presented reveal that active meditation practice deliberately engages networks related to cognitive and attentional control that effectively directs the focus of attention and curbs our usual mode of getting carried away by the endless stream of internal and external distractions. Furthermore, we showed that this active state is carried over to an immediate and passive restful state with similar network relationships than the active state. The trait effects of meditation suggest a recalibration and reconfiguration of network structure, or homeostatic plasticity (Davis, 2013; Hellyer et al., 2017), that produces in par- ticular reductions in DMN activity and connectivity. However, the way this suppression is achieved depends on the stage of meditation. Intermediate meditators show stronger anti-correlated coupling between CEN and DMN (Mooneyham et al., 2017; Marusak et al., 2018), which suggests increased frequency between states of mindlessness and mindfulness and thus moments of DMN suppression, even without being actively engaged in meditation. Finally, with more experience in meditation, the moments of mindfulness become so frequent that no more transitions are needed and thus become the new default mode with sustained reduction in DMN activity and connectivity without effort. These, we think are the trait characteristics that ultimately underlie the beneficial effects of meditation, yet allowing the initial practitioner to increase the number of moments of mindful and clear reality to finally achieve a sustained mindful state, even to see reality as it actually is, without the perturbing vail of past or future illusion.

\section{References}

Andrews-Hanna JR, Smallwood J, Spreng RN (2014) The default network and self-generated thought: component processes, dynamic control, and clinical relevance. Ann NY Acad Sci 1316:2952.

Anticevic A, Cole MW, Murray JD, Corlett PR, Wang X-J, Krystal JH (2012) The role of default network deactivation in cognition and disease. Trends Cogn Sci 16:584-592.

Arens J, Moar KM, Eiden S, Weide K, Schmidt I, Mercer JG, Simon E, Korf H-W (2003) Age-dependent hypothalamic expression of neuropeptides in wild-type and melanocortin-4 receptor-deficient mice. Physiol Genomics 16:38-46.

Arthurs OJ, Boniface S (2002) How well do we understand the neural origins of the fMRI BOLD signal? Trends Neurosci 25:27-31.

Assaf M, Jagannathan K, Calhoun VD, Miller L, Stevens MC, Sahl R, O'Boyle JG, Schultz RT, Pearlson GD (2010) Abnormal functional connectivity of default mode sub-networks in autism spectrum disorder patients. Neuroimage 53:247-256.

Austin JH (1999) Zen and the brain: toward an understanding of meditation and consciousness. Cambridge: The MIT Press.

Baer RA (2003) Mindfulness training as a clinical intervention: a conceptual and empirical review. Clin Psychol Sci Pract 10:125143.

Banks JB, Welhaf MS, Srour A (2015) The protective effects of brief mindfulness meditation training. Conscious Cogn 33:277-285.

Bastos-Leite AJ, Ridgway GR, Silveira C, Norton A, Reis S, Friston KJ (2015) Dysconnectivity within the default mode in first-episode schizophrenia: a stochastic dynamic causal modeling study with functional magnetic resonance imaging. Schizophr Bull 41:144153.

Behzadi Y, Restom K, Liau J, Liu TT (2007) A component based noise correction method (CompCor) for BOLD and perfusion based fMRI. Neuroimage 37:90-101.

Berger H, Hans B (1933) Über das Elektrenkephalogramm des Menschen. Arch Psychiatr Nervenkr 100:301-320.

Biswal B, Yetkin FZ, Haughton VM, Hyde JS (1995) Functional connectivity in the motor cortex of resting human brain using echo-planar MRI. Magn Reson Med 34:537-541.

Bowen S, Witkiewitz K, Clifasefi SL, Grow J, Chawla N, Hsu SH, Carroll HA, Harrop E, Collins SE, Lustyk MK, Larimer ME (2014) Relative efficacy of mindfulness-based relapse prevention, standard relapse prevention, and treatment as usual for substance use disorders: a randomized clinical trial. JAMA Psychiatry 71:547556.

Brewer JA, Worhunsky PD, Gray JR, Tang YY, Weber J, Kober H (2011) Meditation experience is associated with differences in 
default mode network activity and connectivity. Proc Natl Acad Sci USA 108:20254-20259.

Broyd SJ, Demanuele C, Debener S, Helps SK, James CJ, SonugaBarke EJS (2009) Default-mode brain dysfunction in mental disorders: a systematic review. Neurosci Biobehav Rev 33:279-296.

Buchholz L (2015) Exploring the promise of mindfulness as medicine. JAMA 314:1327-1329.

Buckner RL, Andrews-Hanna JR, Schacter DL (2008) The brain's default network. Ann NY Acad Sci 1124:1-38

Bueno VF, Kozasa EH, da Silva MA, Alves TM, Louzã MR, Pompéia $S$ (2015) Mindfulness meditation improves mood, quality of life, and attention in adults with attention deficit hyperactivity disorder. Biomed Res Int 2015:962857.

Camchong J, MacDonald AW 3rd, Bell C, Mueller BA, Lim KO (2011) Altered functional and anatomical connectivity in schizophrenia. Schizophr Bull 37:640-650.

Chai XJ, Castañón AN, Ongür D, Whitfield-Gabrieli S (2012) Anticorrelations in resting state networks without global signal regression. Neuroimage 59:1420-1428.

Chai XJ, Ofen N, Gabrieli JDE, Whitfield-Gabrieli S (2014) Selective development of anticorrelated networks in the intrinsic functional organization of the human brain. J Cogn Neurosci 26:501-513.

Chen AC, Oathes DJ, Chang C, Bradley T, Zhou Z-W, Williams LM, Glover GH, Deisseroth K, Etkin A (2013) Causal interactions between fronto-parietal central executive and default-mode networks in humans. Proc Natl Acad Sci USA 110:19944-19949.

Chien WT, Thompson DR (2014) Effects of a mindfulness-based psychoeducation programme for Chinese patients with schizophrenia: 2-year follow-up. Br J Psychiatry 205:52-59.

Christoff K, Irving ZC, Fox KCR, Spreng RN, Andrews-Hanna JR (2016) Mind-wandering as spontaneous thought: a dynamic framework. Nat Rev Neurosci 17:718-731.

Creswell JD (2015) Biological pathways linking mindfulness with health. In: Handbook of mindfulness: science and practice. New York: Guilford Publications.

Creswell JD, Taren AA, Lindsay EK, Greco CM, Gianaros PJ, Fairgrieve A, Marsland AL, Brown KW, Way BM, Rosen RK, Ferris JL (2016) Alterations in resting-state functional connectivity link mindfulness meditation with reduced interleukin-6: a randomized controlled trial. Biol Psychiatry 80:53-61.

Davis GW (2013) Homeostatic signaling and the stabilization of neural function. Neuron 80:718-728.

Delli Pizzi S, Chiacchiaretta P, Mantini D, Bubbico G, Ferretti A, Edden RA, Di Giulio C, Onofrj M, Bonanni L (2017) Functional and neurochemical interactions within the amygdala-medial prefrontal cortex circuit and their relevance to emotional processing. Brain Struct Funct 222:1267-1279.

Doll A, Hölzel BK, Boucard CC, Wohlschläger AM, Sorg C (2015) Mindfulness is associated with intrinsic functional connectivity between default mode and salience networks. Front Hum Neurosci 9:461.

Dosenbach NUF, Fair DA, Miezin FM, Cohen AL, Wenger KK, Dosenbach RAT, Fox MD, Snyder AZ, Vincent JL, Raichle ME, Schlaggar BL, Petersen SE (2007) Distinct brain networks for adaptive and stable task control in humans. Proc Natl Acad Sci USA 104:1107311078.

Eisendrath SJ, Delucchi K, Bitner R, Fenimore P, Smit M, McLane M (2008) Mindfulness-based cognitive therapy for treatmentresistant depression: a pilot study. Psychother Psychosom 77: 319-320.

Esposito R, Cieri F, Chiacchiaretta P, Cera N, Lauriola M, Di Giannantonio M, Tartaro A, Ferretti A (2018) Modifications in resting state functional anticorrelation between default mode network and dorsal attention network: comparison among young adults, healthy elders and mild cognitive impairment patients. Brain Imaging Behav 12:127-141.

Fountain-Zaragoza S, Prakash RS (2017) Mindfulness training for healthy aging: impact on attention, well-being, and inflammation. Front Aging Neurosci 9:11.
Fox KCR, Nijeboer S, Dixon ML, Floman JL, Ellamil M, Rumak SP, Sedlmeier P, Christoff K (2014) Is meditation associated with altered brain structure? A systematic review and meta-analysis of morphometric neuroimaging in meditation practitioners. Neurosci Biobehav Rev 43:48-73.

Fox MD, Greicius M (2010) Clinical applications of resting state functional connectivity. Front Syst Neurosci 4:19.

Fox MD, Snyder AZ, Vincent JL, Corbetta M, Van Essen DC, Raichle ME (2005) The human brain is intrinsically organized into dynamic, anticorrelated functional networks. Proc Natl Acad Sci USA 102: 9673-9678.

Fransson P (2005) Spontaneous low-frequency BOLD signal fluctuations: an $\mathrm{fMRI}$ investigation of the resting-state default mode of brain function hypothesis. Hum Brain Mapp 26:15-29.

Franzmeier N, Caballero MÁA, Taylor ANW, Simon-Vermot L, Buerger K, Ertl-Wagner B, Mueller C, Catak C, Janowitz D, Baykara E, Gesierich B, Duering M, Ewers M; Alzheimer's Disease Neuroimaging Initiative (2017) Resting-state global functional connectivity as a biomarker of cognitive reserve in mild cognitive impairment. Brain Imaging Behav 11:368-382.

Garland EL, Gaylord SA, Boettiger CA, Howard MO (2010) Mindfulness training modifies cognitive, affective, and physiological mechanisms implicated in alcohol dependence: results of a randomized controlled pilot trial. J Psychoactive Drugs 42:177-192.

Garrison KA, Scheinost D, Constable RT, Brewer JA (2014) BOLD signal and functional connectivity associated with loving kindness meditation. Brain Behav 4:337-347.

Garrison KA, Zeffiro TA, Scheinost D, Constable RT, Brewer JA (2015) Meditation leads to reduced default mode network activity beyond an active task. Cogn Affect Behav Neurosci 15:712-720. Garrity A (2007) Aberrant "default mode" functional connectivity in schizophrenia. Am J Psychiatry 164:450.

Goldberg SB, Tucker RP, Greene PA, Davidson RJ, Wampold BE, Kearney DJ, Simpson TL (2018) Mindfulness-based interventions for psychiatric disorders: a systematic review and meta-analysis. Clin Psychol Rev 59:52-60.

Greicius M (2008) Resting-state functional connectivity in neuropsychiatric disorders. Curr Opin Neurol 21:424-430.

Greicius MD, Krasnow B, Reiss AL, Menon V (2003) Functional connectivity in the resting brain: a network analysis of the default mode hypothesis. Proc Natl Acad Sci USA 100:253-258.

Greicius MD, Srivastava G, Reiss AL, Menon V (2004) Default-mode network activity distinguishes Alzheimer's disease from healthy aging: evidence from functional MRI. Proc Natl Acad Sci USA 101:4637-4642.

Grossman P, Niemann L, Schmidt S, Walach H (2004) Mindfulnessbased stress reduction and health benefits. A meta-analysis. J Psychosom Res 57:35-43.

Guglietti CL, Daskalakis ZJ, Radhu N, Fitzgerald PB, Ritvo P (2013) Meditation-related increases in GABAB modulated cortical inhibition. Brain Stimul 6:397-402.

Gu J, Strauss C, Bond R, Cavanagh K (2015) How do mindfulnessbased cognitive therapy and mindfulness-based stress reduction improve mental health and wellbeing? A systematic review and meta-analysis of mediation studies. Clin Psychol Rev 37:1-12.

Gusnard DA, Raichle ME, Raichle ME (2001) Searching for a baseline: functional imaging and the resting human brain. Nat Rev Neurosci 2:685-694.

Hampson M, Driesen N, Roth JK, Gore JC, Constable RT (2010) Functional connectivity between task-positive and task-negative brain areas and its relation to working memory performance. Magn Reson Imaging 28:1051-1057.

Hart W (2011) The art of living: Vipassana meditation as taught by S.N. Goenka. Onalaska: Pariyatti.

Hasenkamp W, Barsalou LW (2012) Effects of meditation experience on functional connectivity of distributed brain networks. Front Hum Neurosci 6:38.

Hasenkamp W, Wilson-Mendenhall CD, Duncan E, Barsalou LW (2012) Mind wandering and attention during focused meditation: a 
fine-grained temporal analysis of fluctuating cognitive states. Neuroimage 59:750-760.

Hellyer PJ, Clopath C, Kehagia AA, Turkheimer FE, Leech R (2017) From homeostasis to behavior: Balanced activity in an exploration of embodied dynamic environmental-neural interaction. PLoS Comput Biol 13:e1005721.

Hölzel BK, Carmody J, Vangel M, Congleton C, Yerramsetti SM, Gard T, Lazar SW (2011a) Mindfulness practice leads to increases in regional brain gray matter density. Psychiatry Res 191:36-43.

Hölzel BK, Lazar SW, Gard T, Schuman-Olivier Z, Vago DR, Ott U (2011b) How does mindfulness meditation Wwork? Proposing mechanisms of action from a conceptual and neural perspective. Perspect Psychol Sci 6:537-559.

Huettel SA (2004) Linking hemodynamic and electrophysiological measures of brain activity: evidence from functional MRI and intracranial field potentials. Cereb Cortex 14:165-173.

Jang JH, Jung WH, Kang D-H, Byun MS, Kwon SJ, Choi C-H, Kwon JS (2011) Increased default mode network connectivity associated with meditation. Neurosci Lett 487:358-362.

Janssen L, Kan CC, Carpentier PJ, Sizoo B, Hepark S, Grutters J, Donders R, Buitelaar JK, Speckens AEM (2015) Mindfulness based cognitive therapy versus treatment as usual in adults with attention deficit hyperactivity disorder (ADHD). BMC Psychiatry 15:216.

Jao T, Li CW, Vértes PE, Wu CW, Achard S, Hsieh CH, Liou CH, Chen JH, Bullmore ET (2016) Large-scale functional brain network reorganization during Taoist meditation. Brain Connect 6:9-24.

Jazaieri H, Hooria J, Lee IA, Kelly M, Thupten J, Doty JR, Gross JJ, Goldin PR (2016) A wandering mind is a less caring mind: daily experience sampling during compassion meditation training. $\mathrm{J}$ Posit Psychol 11:37-50.

Jindal V, Gupta S, Das R (2013) Molecular mechanisms of meditation. Mol Neurobiol 48:808-811.

Kane MJ, Gross GM, Chun CA, Smeekens BA, Meier ME, Silvia PJ, Kwapil TR (2017) For whom the mind wanders, and when, varies across laboratory and daily-life settings. Psychol Sci 28:12711289.

Keller JB, Hedden T, Thompson TW, Anteraper SA, Gabrieli JDE, Whitfield-Gabrieli S (2015) Resting-state anticorrelations between medial and lateral prefrontal cortex: association with working memory, aging, and individual differences. Cortex 64:271-280.

Kelly AMC, Uddin LQ, Biswal BB, Castellanos FX, Milham MP (2008) Competition between functional brain networks mediates behavioral variability. Neuroimage 39:527-537.

Kemmer PB, Guo Y, Wang Y, Pagnoni G (2015) Network-based characterization of brain functional connectivity in Zen practitioners. Front Psychol 6:603.

Killingsworth MA, Gilbert DT (2010) A wandering mind is an unhappy mind. Science 330:932.

Kong F, Hu S, Wang X, Song Y, Liu J (2015) Neural correlates of the happy life: the amplitude of spontaneous low frequency fluctuations predicts subjective well-being. Neuroimage 107:136-145.

Kuyken W, Byford S, Taylor RS, Watkins E, Holden E, White K, Barrett B, Byng R, Evans A, Mullan E, Teasdale JD (2008) Mindfulness-based cognitive therapy to prevent relapse in recurrent depression. J Consult Clin Psychol 76:966-978.

Liao W, Zhang Z, Pan Z, Mantini D, Ding J, Duan X, Luo C, Wang Z, Tan Q, Lu G, Chen H (2011) Default mode network abnormalities in mesial temporal lobe epilepsy: a study combining fMRI and DTI. Hum Brain Mapp 32:883-895.

Luders E, Toga AW, Lepore N, Gaser C (2009) The underlying anatomical correlates of long-term meditation: larger hippocampal and frontal volumes of gray matter. Neuroimage 45:672-678.

Ludwig DS, Kabat-Zinn J (2008) Mindfulness in medicine. JAMA 300:1350-1352.

Lutz A, Antoine L, Dunne JD, Davidson RJ (2007) Meditation and the neuroscience of consciousness: an introduction. In: The Cambridge handbook of consciousness, pp 499-552. Cambridge: Cambridge University Press.
Lutz J, Herwig U, Opialla S, Hittmeyer A, Jäncke L, Rufer M, Grosse Holtforth M, Brühl AB (2014) Mindfulness and emotion regulation-an fMRI study. Soc Cogn Affect Neurosci 9:776-785.

Mantini D, Corbetta M, Romani GL, Orban GA, Vanduffel W (2013) Evolutionarily novel functional networks in the human brain? $\mathrm{J}$ Neurosci 33:3259-3275.

Martínez AY, Demertzi A, Bauer CCC, Gracia-Tabuenca Z, Alcauter S, Barrios FA (2019) The Time Varying Networks of the Interoceptive Attention and Rest. BioRxiv. Advance online publication Team. Retrieved November 13, 2019. doi:10.1101/840645.

Marusak HA, Thomason ME, Elrahal F, Peters CA, Kundu P, Lombardo MV, Calhoun VD, Goldberg EK, Cohen C, Taub JW, Rabinak CA (2018) Mindfulness and dynamic functional neural connectivity in children and adolescents. 336:211-218.

Ma SH, Teasdale JD (2004) Mindfulness-based cognitive therapy for depression: replication and exploration of differential relapse prevention effects. J Consult Clin Psychol 72:31-40.

Mason MF, Norton MI, Van Horn JD, Wegner DM, Grafton ST, Macrae CN (2007) Wandering minds: the default network and stimulus-independent thought. Science 315:393-395.

McKiernan KA, Kaufman JN, Kucera-Thompson J, Binder JR (2003) A parametric manipulation of factors affecting task-induced deactivation in functional neuroimaging. J Cogn Neurosci 15:394-408.

Mooneyham BW, Mrazek MD, Mrazek AJ, Schooler JW (2016) Signal or noise: brain network interactions underlying the experience and training of mindfulness. Ann NY Acad Sci 1369:240-256.

Mooneyham BW, Mrazek MD, Mrazek AJ, Mrazek KL, Phillips DT, Schooler JW (2017) States of mind: characterizing the neural bases of focus and mind-wandering through dynamic functional connectivity. J Cogn Neurosci 29:495-506.

Moore A, Gruber T, Derose J, Malinowski P (2012) Regular, brief mindfulness meditation practice improves electrophysiological markers of attentional control. Front Hum Neurosci 6:18.

Mrazek MD, Franklin MS, Phillips DT, Baird B, Schooler JW (2013) Mindfulness training improves working memory capacity and GRE performance while reducing mind wandering. Psychol Sci 24:776781.

Muraskin J, Dodhia S, Lieberman G, Garcia JO, Verstynen T, Vettel JM, Sherwin J, Sajda P (2016) Brain dynamics of post-task resting state are influenced by expertise: insights from baseball players. Hum Brain Mapp 37:4454-4471.

Northoff G, Bermpohl F (2004) Cortical midline structures and the self. Trends Cogn Sci 8:102-107.

Northoff G, Walter M, Schulte RF, Beck J, Dydak U, Henning A, Boeker H, Grimm S, Boesiger P (2007) GABA concentrations in the human anterior cingulate cortex predict negative BOLD responses in fMRI. Nat Neurosci 10:1515-1517.

Ottaviani C, Shapiro D, Couyoumdjian A (2013) Flexibility as the key for somatic health: from mind wandering to perseverative cognition. Biol Psychol 94:38-43.

Pomarol-Clotet E, Salvador R, Sarró S, Gomar J, Vila F, Martínez A, Guerrero A, Ortiz-Gil J, Sans-Sansa B, Capdevila A, Cebamanos JM, McKenna PJ (2008) Failure to deactivate in the prefrontal cortex in schizophrenia: dysfunction of the default mode network? Psychol Med 38:1185-1193.

Prakash RS, Whitmoyer P, Aldao A, Schirda B (2015) Mindfulness and emotion regulation in older and young adults. Aging Ment Health 21:77-87.

Raichle ME (2015) The brain's default mode network. Annu Rev Neurosci 38:433-447.

Rilling JK (2014) Comparative primate neuroimaging: insights into human brain evolution. Trends Cogn Sci 18:46-55.

Saad ZS, Gotts SJ, Kevin M, Gang C, Jo HJ, Alex M, Cox RW (2012) Trouble at rest: how correlation patterns and group differences become distorted after global signal regression. Brain Connect 2:25-32.

Scheibner HJ, Bogler C, Gleich T, Haynes J-D, Bermpohl F (2017) Internal and external attention and the default mode network. Neuroimage 148:381-389. 
Selemon LD, Goldman-Rakic PS (1988) Common cortical and subcortical targets of the dorsolateral prefrontal and posterior parietal cortices in the rhesus monkey: evidence for a distributed neural network subserving spatially guided behavior. J Neurosci 8:40494068.

Servaas MN, Riese $H$, Renken RJ, Wichers $M$, Bastiaansen JA, Figueroa CA, Geugies H, Mocking RJ, Geerligs L, Marsman J-B, Aleman A, Schene AH, Schoevers RA, Ruhé HG (2017) Associations between daily affective instability and connectomics in functional subnetworks in remitted patients with recurrent major depressive disorder. Neuropsychopharmacology 42:2583-2592.

Shapiro DH Jr, Walsh RN (1984) Meditation: classic and contemporary perspectives. Piscataway: Aldine Transactions Publishers.

Shaurya Prakash R, De Leon AA, Klatt M, Malarkey W, Patterson B (2013) Mindfulness disposition and default-mode network connectivity in older adults. Soc Cogn Affect Neurosci 8:112-117.

Sheline YI, Raichle ME (2013) Resting state functional connectivity in preclinical Alzheimer's disease. Biol Psychiatry 74:340-347.

Sheline YI, Barch DM, Price JL, Rundle MM, Vaishnavi SN, Snyder AZ, Mintun MA, Wang S, Coalson RS, Raichle ME (2009) The default mode network and self-referential processes in depression. Proc Natl Acad Sci USA 106:1942-1947.

Shen H, Li Z, Zeng LL, Yuan L, Chen F, Liu Z, Hu D (2014) Internetwork dynamic connectivity effectively differentiates schizophrenic patients from healthy controls. Neuroreport 25:1344-1349.

Shpaner M, Kelly C, Lieberman G, Perelman H, Davis M, Keefe FJ, Naylor MR (2014) Unlearning chronic pain: a randomized controlled trial to investigate changes in intrinsic brain connectivity following cognitive behavioral therapy. Neuroimage Clin 5:365376.

Simon R, Engström M (2015) The default mode network as a biomarker for monitoring the therapeutic effects of meditation. Front Psychol 6:776.

Smallwood J, Fitzgerald A, Miles LK, Phillips LH (2009) Shifting moods, wandering minds: negative moods lead the mind to wander. Emotion 9:271-276.

Smallwood J, O'Connor RC (2011) Imprisoned by the past: unhappy moods lead to a retrospective bias to mind wandering. Cogn Emot 25:1481-1490.

Smith SM, Nichols TE (2009) Threshold-free cluster enhancement: addressing problems of smoothing, threshold dependence and localisation in cluster inference. Neuroimage 44:83-98.

Sonuga-Barke EJS, Castellanos FX (2007) Spontaneous attentional fluctuations in impaired states and pathological conditions: a neurobiological hypothesis. Neurosci Biobehav Rev 31: 977-986.

Sridharan D, Levitin DJ, Menon V (2008) A critical role for the right fronto-insular cortex in switching between central-executive and default-mode networks. Proc Natl Acad Sci USA 105:1256912574.

Tang YY, Tang R, Posner MI (2013) Brief meditation training induces smoking reduction. Proc Natl Acad Sci USA 110:1397113975.

Tang YY, Posner MI, Rothbart MK (2014) Meditation improves selfregulation over the life span. Ann NY Acad Sci 1307:104-111.

Taylor PA, Saad ZS (2013) FATCAT: (an efficient) functional and tractographic connectivity analysis toolbox. Brain Connect 3:523535.

Teasdale JD, Segal ZV, Williams JMG, Ridgeway VA, Soulsby JM, Lau MA (2000) Prevention of relapse/recurrence in major depression by mindfulness-based cognitive therapy. J Consult Clin Psychol 68:615-623.

Turner K (2014) Mindfulness skills training: a pilot study of changes in mindfulness, emotion regulation, and self-perception of aging in older participants. Act Adapt Aging 38:156-167.

Uddin LQ, Kelly AMC, Biswal BB, Margulies DS, Shehzad Z, Shaw D, Ghaffari M, Rotrosen J, Adler LA, Castellanos FX, Milham MP (2008) Network homogeneity reveals decreased integrity of default-mode network in ADHD. J Neurosci Methods 169:249254.
Uddin LQ, Kelly AM, Biswal BB, Castellanos FX, Milham MP (2009) Functional connectivity of default mode network components: correlation, anticorrelation, and causality. Hum Brain Mapp 30: 625-637.

Van Dam NT, van Vugt MK, Vago DR, Schmalzl L, Saron CD, Olendzki A, Meissner T, Lazar SW, Kerr CE, Gorchov J, Fox KCR, Field BA, Britton WB, Brefczynski-Lewis JA, Meyer DE (2018) Mind the hype: a critical evaluation and prescriptive agenda for research on mindfulness and meditation. Perspect Psychol Sci 13:36-61.

Waites AB, Stanislavsky A, Abbott DF, Jackson GD (2005) Effect of prior cognitive state on resting state networks measured with functional connectivity. Hum Brain Mapp 24:59-68.

Wells RE, Kerr CE, Wolkin J, Dossett M, Davis RB, Walsh J, Wall RB, Kong J, Kaptchuk T, Press D, Phillips RS, Yeh G (2013) Meditation for adults with mild cognitive impairment: a pilot randomized trial. J Am Geriatr Soc 61:642-645.

West MA (2016) The psychology of meditation: research and practice. New York: Oxford University Press.

Whitfield-Gabrieli S, Ford JM (2012) Default mode network activity and connectivity in psychopathology. Annu Rev Clin Psychol 8:49-76.

Whitfield-Gabrieli S, Thermenos HW, Milanovic S, Tsuang MT, Faraone SV, McCarley RW, Shenton ME, Green Al, Nieto-Castanon A, LaViolette P, Wojcik J, Gabrieli JDE, Seidman LJ (2009) Hyperactivity and hyperconnectivity of the default network in schizophrenia and in first-degree relatives of persons with schizophrenia. Proc Natl Acad Sci USA 106:1279-1284.

Whitfield-Gabrieli S, Susan WG, Alfonso NC (2012) Conn: a functional connectivity toolbox for correlated and anticorrelated brain networks. Brain Connect 2:125-141.

Willner P, Scheel-Krüger J, Belzung C (2013) The neurobiology of depression and antidepressant action. Neurosci Biobehav Rev 37:2331-2371.

Winkler AM, Ridgway GR, Webster MA, Smith SM, Nichols TE (2014) Permutation inference for the general linear model. Neuroimage 92:381-397.

Witkiewitz K, Alan Marlatt G, Walker D (2005) Mindfulness-based relapse prevention for alcohol and substance use disorders. J Cogn Psychother 19:211-228.

Wu CW, Chen CL, Liu PY, Chao YP, Biswal BB, Lin CP (2011) Empirical evaluations of slice-timing, smoothing, and normalization effects in seed-based, resting-state functional magnetic resonance imaging analyses. Brain Connect 1:401-410.

Yang CC, Barrós-Loscertales A, Pinazo D, Ventura-Campos N, Borchardt $\mathrm{V}$, Bustamante JC, Rodríguez-Pujadas A, Fuentes-Claramonte P, Balaguer R, Ávila C, Walter M (2016) State and training effects of mindfulness meditation on brain networks reflect neuronal mechanisms of its antidepressant effect. Neural Plast 2016:9504642.

Yeo BTT, Krienen FM, Sepulcre J, Sabuncu MR, Lashkari D, Hollinshead M, Roffman JL, Smoller JW, Zöllei L, Polimeni JR, Fischl B, Liu H, Buckner RL (2011) The organization of the human cerebral cortex estimated by intrinsic functional connectivity. J Neurophysiol 106:1125-1165

Zeidan F, Johnson SK, Diamond BJ, David Z, Goolkasian P (2010) Mindfulness meditation improves cognition: evidence of brief mental training. Conscious Cogn 19:597-605.

Zhao XH, Wang PJ, Li CB, Hu ZH, Xi Q, Wu WY, Tang XW (2007) Altered default mode network activity in patient with anxiety disorders: an fMRI study. Eur J Radiol 63:373-378.

Zou QH, Zhu CZ, Yang Y, Zuo XN, Long XY, Cao QJ, Wang YF, Zang YF (2008) An improved approach to detection of amplitude of low-frequency fluctuation (ALFF) for resting-state fMRI: fractional ALFF. J Neurosci Methods 172:137-141.

Zylowska L, Ackerman DL, Yang MH, Futrell JL, Horton NL, Hale TS, Pataki C, Smalley SL (2008) Mindfulness meditation training in adults and adolescents with ADHD: a feasibility study. J Atten Disord 11:737-746. 